\title{
Comparative transcriptomic analysis of follicle- enclosed oocyte maturational and developmental competence acquisition in two non-mammalian vertebrates
}

\author{
Maella Gohin ${ }^{1,2}$, Julien Bobe ${ }^{2^{*}}$, Franck Chesnel $^{1^{*}}$
}

\begin{abstract}
Background: In vertebrates, late oogenesis is a key period during which the oocyte acquires its ability to resume meiosis (i.e. maturational competence) and to develop, once fertilized, into a normal embryo (i.e. developmental competence). However, the molecular mechanisms involved in these key biological processes are far from being fully understood. In order to identify key mechanisms conserved among teleosts and amphibians, we performed a comparative analysis using ovarian tissue sampled at successive steps of the maturational competence acquisition process in the rainbow trout (Oncorhynchus mykiss) and in the clawed toad (Xenopus laevis). Our study aimed at identifying common differentially expressed genes during late oogenesis in both species. Using an existing transcriptomic analysis that had previously been carried out in rainbow trout, candidate genes were selected for subsequent quantitative PCR-based comparative analysis.

Results: Among the 1200 differentially expressed clones in rainbow trout, twenty-six candidate genes were selected for further analysis by real-time PCR in both species during late oogenesis. Among these genes, eight had similar expression profiles in trout and Xenopus. Six genes were down-regulated during oocyte maturation (cyp19a1, cyp17a1, tescalcin, tfr1, cmah, hsd11b3) while two genes exhibited an opposite pattern (apoc1, star). In order to document possibly conserved molecular mechanisms, four genes (star, cyp19a1, cyp17a1 and hsd1163) were further studied due to their known or suspected role in steroidogenesis after characterization of the orthology relationships between rainbow trout and Xenopus genes. Apoc1 was also selected for further analysis because of its reported function in cholesterol transport, which may modulate steroidogenesis by regulating cholesterol bioavailability in the steroidogenic cells.

Conclusions: We have successfully identified orthologous genes exhibiting conserved expression profiles in the ovarian follicle during late oogenesis in both trout and Xenopus. While some identified genes were previously uncharacterized during Xenopus late oogenesis, the nature of these genes has pointed out molecular mechanisms possibly conserved in amphibians and teleosts. It should also be stressed that in addition to the already suspected importance of steroidogenesis in maturational competence acquisition, our approach has shed light on other regulatory pathways which may be involved in maturational and developmental competence acquisitions that will require further studies.
\end{abstract}

\footnotetext{
* Correspondence: Julien.bobe@rennes.inra.fr; Franck.chesnel@univ-rennes1.fr ${ }^{1}$ CNRS/IGDR (UMR 6061), IFR140 GFAS, Université de Rennes I, 2, Avenue du Pr. Léon Bernard, 35043 Rennes Cedex, France

${ }^{2}$ Institut National de la Recherche Agronomique, INRA SCRIBE, UR1037,

IFR140 GFAS, Campus de Beaulieu, 35000 Rennes Cedex, France
} 


\section{Background}

Late oogenesis is a key period in the complex process ultimately leading to the release of the female gamete from the ovary. During this period, the oocyte undergoes meiotic maturation (also known as oocyte maturation), a process leading to an oocyte that will remain arrested in metaphase II until fertilization. The ovulatory process that allows the release of the oocyte from the ovarian follicle also takes place during late oogenesis. Both oocyte maturation and ovulation have been extensively studied in vertebrates [1-4]. However, other key biological processes that also occur in the ovary during late oogenesis have received far less attention. During this time period, the oocyte acquires not only its ability to resume meiosis, once hormonally stimulated, but also its ability to develop, once fertilized, into a normal embryo. These two processes are referred to as maturational competence acquisition and developmental competence acquisition, respectively. They both rely on events that could occur very early in the oogenetic process. For example, the accumulation of maternallyinherited mRNAs into the oocyte that can occur very early during oogenesis is known to support embryonic development until the activation of the zygotic genome $[2,5,6]$. It is also noteworthy that oocyte-somatic cell interactions and communications participate, at least in mammals, in the acquisition of the ability of the oocyte to resume meiosis, to be ovulated, to be fertilized, and to subsequently develop into a normal embryo [7]. Nevertheless, maturational and developmental competence acquisitions remain poorly understood, especially in non-mammalian vertebrates in which available data remain scarce. This problem is further complicated by the large variety of ovarian development types found among those species. In teleosts for instance, the dynamics of follicular recruitment can be extremely variable in comparison to what is seen in mammals [8]. It should however be stressed that amphibians and teleosts share a common ovarian follicular structure that is also very different from the mammalian follicle in which an antrum is formed during late folliculogenesis [2]. This common feature could suggest that conserved mechanisms may exist among these two non-mammalian vertebrate groups. In an attempt to identify conserved molecular mechanisms underlying oocyte development, the present study was designed to identify common genes that are differentially expressed by the ovarian follicles during late oogenesis in a teleost fish and an amphibian. The rainbow trout (Oncorhynchus mykiss) and the south-African clawed toad (Xenopus laevis) were selected because both species have significant genomic resources and a large background in oocyte maturation studies $[9,10]$. Moreover, Xenopus ovarian development is asynchronous and follicles of all stages (I-VI) can be found in the same ovary at any time [11]. While this type of ovarian development can also be found in numerous teleosts, the rainbow trout has, in contrast, a group-synchronous ovarian development type and all follicles of a single clutch develop simultaneously once a year [12]. Thus, we aimed at identifying molecular mechanisms that would be conserved among the two studied vertebrate groups despite existing differences in ovarian development types. Indeed, it should be stressed that amphibians and teleosts share common mechanisms such as the predominant role of progesterone or a progestin, the maturation-inducing steroid, in the induction of meiosis resumption $[10,13]$. To achieve our goal, differentially expressed genes were selected from an existing microarray study previously carried out in rainbow trout [14] and subsequently studied in both species using quantitative PCR (QPCR). The comparative QPCR-based analysis was carried out during late oogenesis at successive steps of maturational competence acquisition in both species. Finally, the nature of some common molecular mechanisms was highlighted through a deeper analysis of specific genes encoding proteins with known or suspected functions in steroidogenesis.

\section{Results}

\section{Candidate genes selection}

In a previous study, a microarray analysis was carried out during rainbow trout late oogenesis [14] and data subsequently deposited in Gene Expression Omnibus database (GEO Series accession number GSE4871). This existing dataset was reanalyzed and used to select candidate genes for the QPCR-based comparative analysis carried out hereafter. A Significance Analysis of Microarray (SAM) procedure with a false discovery rate (FDR) of $5 \%$ was performed in the present study and resulted in the identification of 1200 differentially expressed genes (Fig. 1A). The clustering analysis of these 1200 clones resulted in the identification of two major clusters of genes. The first cluster contained 891 clones that were down-regulated throughout post-vitellogenesis and oocyte maturation. In contrast, the second cluster contained 309 clones that were up-regulated during oocyte maturation. Among the 1200 differentially expressed genes, $88 \%$ were annotated with at least one GO biological process term (Table 1). Among the most enriched biological processes associated with cluster 1 genes, several ones appeared to be involved in DNA/RNA metabolism and post-translational modifications [see Additional file 1]. When considering cluster 2 genes, the enrichment analysis brought up biological processes involved in the regulation of transcription, cell cycle 


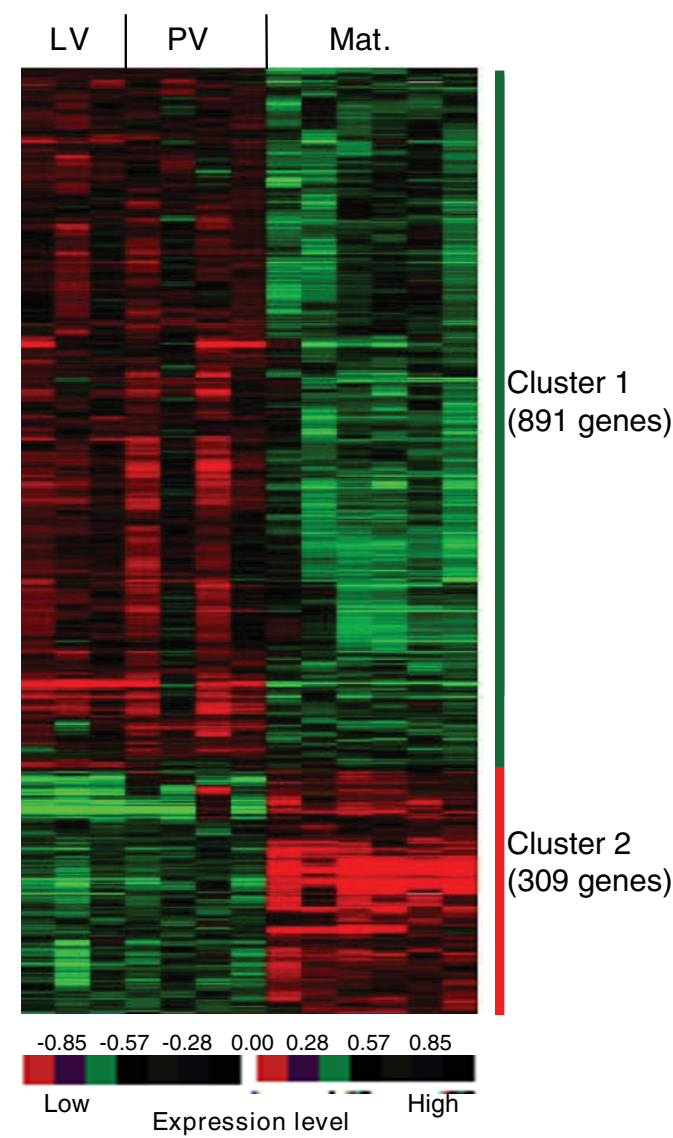

Figure 1 Gene expression profiling during rainbow trout late oogenesis Supervised average linkage clustering analysis of 1200 clones in rainbow trout ovary during late vitellogenesis ( $L V, n=3)$, post-vitellogenesis ( $P V, n=4)$ and during maturation (Mat., $n=6$ ). Each row represents a gene and each column an ovarian RNA sample. The 13 samples are supervised according to the natural time-course of oogenesis. Data were log2-transformed and mediancentered prior to the clustering analysis. For each gene the expression level within sample set is indicated using a color density scale. Red and green are used for over- and under-expression respectively, while black is used for median expression.

Table 1 Number of Gene Ontology (GO) functional annotation terms associated with differentially expressed genes using DAVID software

\begin{tabular}{cccc}
\hline & $\begin{array}{c}\text { Number of } \\
\text { differentially } \\
\text { expressed genes }\end{array}$ & $\begin{array}{c}\text { GO } \\
\text { annotated } \\
\text { genes }\end{array}$ & $\begin{array}{c}\text { genes with } \\
\text { associated GO } \\
\text { biological process }\end{array}$ \\
\hline Total & 1200 & $\begin{array}{c}1059 \\
(88.25 \%)\end{array}$ & $1056(88 \%)$ \\
$\begin{array}{c}\text { Cluster } \\
1\end{array}$ & 891 & $764(85.75 \%)$ & $759(85.18 \%)$ \\
$\begin{array}{c}\text { Cluster } \\
2\end{array}$ & 309 & $304(98.38 \%)$ & $297(96.12 \%)$ \\
\hline
\end{tabular}

The number of differentially expressed genes, the number and percentage of genes associated with at least one GO functional annotation term, and the number and percentage of genes associated with at least one GO biological process term are indicated. Clusters 1 and 2 correspond to the gene clusters presented in fig. 1. progression, cell adhesion and cell communication [see Additional file 2].

Together, these functions are consistent with the various physiological processes undergone by the follicleenclosed oocyte during the preovulatory period (i.e. ovulation, fertilization and embryo development) [1].

Twenty-three genes exhibiting at least a two-fold change in expression between late/post-vitellogenesis and oocyte maturation were selected among the differentially expressed genes (Table 2) for the QPCR-based comparative analysis. In addition, three genes (11 3 3hydroxysteroid dehydrogenase $h s d 11 b 3$, the connexin $c \times 32.2$ and the transcription factor etv5) that exhibited a lower differential expression were also kept for further analysis based on their putative role in oocyte maturational and developmental competence acquisition $[15,16]$. A total of 26 genes was thus kept for further QPCR-based comparative analysis (Table 2). Xenopus sequences were identified by a reciprocal best blast hit strategy using the rainbow trout sequence as a query. Accession number and symbol of Xenopus genes are also shown in table 2 . These genes are involved in different cellular functions such as metabolic processes, trafficking, proteolysis, transcription, cell cycle, and post-translational protein modifications.

QPCR-based comparative analysis during late oogenesis In rainbow trout, a differential expression was demonstrated for 24 genes out of 26 (Fig. 2). For those 24 genes, the expression ratios calculated from QPCR and microarray data are consistent even if some limited differences exist, mostly due to the underestimation of highest differential expression by nylon array technology (Table 2). Six genes belonging to cluster 1 (cyp19a1a, cyp17a1, tescalcin, tfr1, cmah, hsd11b3) showed a decreased expression during maturation. Eighteen genes belonging to cluster 2 exhibited an increased mRNA expression throughout late oogenesis. These genes are mostly related to proteolysis, regulation of transcription, cell cycle and cellular junctions. Contrarily to the results of the microarray analysis, two genes (rbm39a and rgs18) showed a stable expression profile throughout late oogenesis. In Xenopus, 24 among the 26 assayed genes were down-regulated during late vitellogenesis and/or maturation whereas only 2 genes (the apolipoprotein apoC1, and the STeroidogenic Acute Regulatory protein star-A) showed a sharp increase of mRNA expression during late vitellogenesis or at the time of oocyte maturation, respectively (Fig. 2). In summary, eight genes shared similar expression profiles in both rainbow trout and Xenopus during late oogenesis. Among these genes, six were down-regulated during oocyte maturation (cyp19a1a, cyp17a1, tescalcin, tfr 1 , cmah, hsd11b3) while two exhibited an opposite pattern (apoc1, star). 
Table 2 Genes assayed by QPCR in ovarian samples from Oncorhynchus mykiss and from Xenopus laevis

\begin{tabular}{|c|c|c|c|c|c|c|c|c|c|c|c|c|c|}
\hline \multirow{3}{*}{ target genes } & \multicolumn{8}{|c|}{ Oncorhynchus mykiss } & \multicolumn{5}{|c|}{ Xenopus laevis } \\
\hline & \multirow[t]{2}{*}{ symbol } & \multirow[t]{2}{*}{ GenBank\# } & $\begin{array}{l}\text { LV/ } \\
\mathrm{PV}\end{array}$ & $\begin{array}{l}\text { LV/ } \\
\text { MAT }\end{array}$ & $\begin{array}{l}\text { PV/ } \\
\text { MAT }\end{array}$ & $\begin{array}{l}\text { LV/ } \\
\text { PV }\end{array}$ & $\begin{array}{l}\text { LV/ } \\
\text { MAT }\end{array}$ & $\begin{array}{l}\text { PV/ } \\
\text { MAT }\end{array}$ & \multirow[t]{2}{*}{ symbol } & \multirow[t]{2}{*}{ GenBank\# } & $\begin{array}{l}\mathrm{IV} / \\
\mathrm{VI} \\
\end{array}$ & $\begin{array}{l}\text { IV/ } \\
\text { MAT }\end{array}$ & $\begin{array}{c}\mathrm{VI} / \\
\text { MAT }\end{array}$ \\
\hline & & & \multicolumn{3}{|c|}{ microarray ratio } & \multicolumn{3}{|c|}{ QPCR ratio } & & & \multicolumn{3}{|c|}{ QPCR ratio } \\
\hline *Aromatase & cyp19a1a & BX083177 & 2.58 & 25 & 9.67 & 2.6 & 182 & 76 & $\begin{array}{c}\text { P450arom- } \\
\text { A }\end{array}$ & NM_001085653 & 313 & 1237 & 3.95 \\
\hline $\begin{array}{l}{ }^{*} \text { Cytochrome P450 } \\
17 \mathrm{~A} 1\end{array}$ & cyp17a1 & BX072662 & 0.84 & 2.46 & 2.92 & 1.15 & 4.7 & 4.5 & сур17a1 & AF325435 & 2.41 & 3.77 & 1.56 \\
\hline $\begin{array}{l}\text { * RNA-binding } \\
\text { region-containing } \\
\text { protein } 39\end{array}$ & rbm39a & BX081888 & 1.77 & 3.06 & 1.73 & 0.59 & 0.52 & 0.99 & rbm39 & BC077813 & 1.68 & 2.25 & 1.34 \\
\hline $\begin{array}{l}\text { * A disintegrin and } \\
\text { metalloproteinase } \\
\text { domain } 8\end{array}$ & adam8a & BX871415 & 0.50 & 0.23 & 0.45 & 1.18 & 0.10 & 0.18 & & & & & \\
\hline $\begin{array}{l}\text { A disintegrin and } \\
\text { metalloproteinase } \\
\text { domain } 13\end{array}$ & adam13 & NM_001087445 & 2.28 & 2.94 & 1.29 & & & & & & & & \\
\hline $\begin{array}{l}\text { * A disintegrin and } \\
\text { metalloproteinase } \\
\text { domain } 22\end{array}$ & $\operatorname{adam} 22$ & CA363158 & 1.00 & 0.42 & 0.42 & 0.47 & 0.14 & 0.30 & & & & & \\
\hline $\begin{array}{l}\text { A disintegrin and } \\
\text { metalloproteinase } \\
\text { domain } 11\end{array}$ & $m d c 11 b$ & NM_001087444 & 1.41 & 1.65 & 1.17 & & & & & & & & \\
\hline $\begin{array}{l}\text { * Protein kinase C } \\
\text { delta type }\end{array}$ & prkcd & CA372310 & 1.02 & 0.52 & 0.51 & 0.77 & 0.09 & 0.12 & pkc-delta2 & NM_001090993 & 1.43 & 2.19 & 1.52 \\
\hline $\begin{array}{l}\text { * Serum/ } \\
\text { glucocorticoid } \\
\text { related kinase } 2\end{array}$ & sgk2 & CA387850 & 0.99 & 0.24 & 0.24 & 0.01 & 0.0007 & 0.08 & sgkla & NM_001090340 & 2.97 & 1.72 & 0.58 \\
\hline * Serine protease 23 & prss23 & BX087643 & 0.53 & 0.26 & 0.49 & 0.21 & 0.07 & 0.35 & prss23 & CD255705 & 2.79 & 7.85 & 2.82 \\
\hline $\begin{array}{l}\text { * Regulator of G- } \\
\text { protein signaling } 18\end{array}$ & $\operatorname{rgs} 18$ & BX876662 & 1.04 & 0.42 & 0.40 & 0.94 & 0.98 & 1.18 & $\operatorname{rgs} 18$ & NM_001092321 & 1.95 & 2.17 & 1.11 \\
\hline * Forkhead box O5 & foxo5 & BX885992 & 0.91 & 0.32 & 0.35 & 0.55 & 0.10 & 0.19 & & & & & \\
\hline Forkhead box $\mathrm{O} 3$ & foxo3 & NM_001092949 & 1.94 & 1.85 & 0.95 & & & & & & & & \\
\hline $\begin{array}{l}\text { * Cytidine } \\
\text { monophosphate-N- } \\
\text { acetylneuraminic } \\
\text { acid hydroxylase }\end{array}$ & cmah & BX878414 & 1.28 & 5.88 & 4.58 & 1.26 & 10.57 & 9.26 & cmah & NM_001086828 & 7.26 & 6.16 & 0.85 \\
\hline $\begin{array}{l}{ }^{*} \text { Steroidogenic } \\
\text { acute regulatory } \\
\text { protein }\end{array}$ & star & BX079021 & 0.81 & 0.34 & 0.41 & 0.56 & 0.20 & 0.35 & star-A & AF220437 & 0.23 & 0.02 & 0.10 \\
\hline $\begin{array}{l}\text { * Growth arrest and } \\
\text { DNA-damage- } \\
\text { inducible protein } \\
\text { beta }\end{array}$ & gadd45bii & CA363171 & 0.83 & 0.36 & 0.43 & 0.59 & 0.14 & 0.26 & gadd45b & DT070441 & 2.41 & 2.89 & 1.20 \\
\hline${ }^{*}$ Apolipoprotein $\mathrm{Cl}$ & apocl & CA353171 & 0.27 & 0.14 & 0.53 & 0.26 & 0.13 & 0.52 & apocl & DQ096911 & 0.23 & 0.40 & 1.75 \\
\hline $\begin{array}{l}\text { *11-beta } 3- \\
\text { hydroxysteroid } \\
\text { dehydrogenase }\end{array}$ & hsd11b3 & CA348069 & 0.83 & 1.2 & 1.45 & 1.29 & 3.69 & 2.97 & hsd11b3 & BC106472 & 2.18 & 3.09 & 1.41 \\
\hline $\begin{array}{l}\text { * Receptor-type } \\
\text { tyrosine-protein } \\
\text { phosphatase F }\end{array}$ & ptprf & CA360891 & 0.68 & 0.38 & 0.56 & 0.69 & 0.28 & 0.43 & $x p t p-d$ & NM_001090381 & 2.71 & 8.97 & 3.31 \\
\hline * Dystrophin & $d m d$ & CA377239 & 0.83 & 0.11 & 0.13 & 0.53 & 0.55 & 0.84 & $d m d$ & X99700 & 2.11 & 2.38 & 1.13 \\
\hline * Cyclin L1 & ccnl1 & BX863114 & 0.79 & 0.55 & 0.70 & 1.01 & 0.65 & 0.64 & ccn/1 & BC073707 & 1.40 & 1.66 & 1.19 \\
\hline $\begin{array}{l}\text { *Transferrin } \\
\text { receptor protein } 1\end{array}$ & tfr1 & BX860777 & 1.36 & 3.07 & 2.26 & 1.47 & 3.41 & 2.50 & tfr1 & CA790915 & 1.98 & 7.12 & 3.58 \\
\hline${ }^{*}$ C-ETS-2 protein & ets2 & CA368141 & 0.99 & 0.39 & 0.39 & 1.11 & 0.36 & 0.34 & $e t s 2 b$ & X52635 & 1.40 & 1.96 & 1.40 \\
\hline $\begin{array}{l}\text { * ETS translocation } \\
\text { variant } 5\end{array}$ & etv5 & BX870637 & 0.98 & 0.71 & 0.74 & 0.59 & 0.62 & 1.18 & & & & & \\
\hline XER81 & xer81 & AF057565 & 1.38 & 1.69 & 1.22 & & & & & & & & \\
\hline
\end{tabular}


Table 2: Genes assayed by QPCR in ovarian samples from Oncorhynchus mykiss and from Xenopus laevis (Continued)

\begin{tabular}{|c|c|c|c|c|c|c|c|c|c|c|c|c|c|}
\hline $\begin{array}{l}\text { * Gap junction } \\
\text { Connexin-32.2 } \\
\text { protein }\end{array}$ & $c \times 32.2$ & BX082081 & 0.96 & 1.2 & 1.25 & 0.17 & 0.13 & 0.82 & $c \times 32$ & DQ096928 & 1.28 & 2.45 & 1.91 \\
\hline $\begin{array}{l}\text { * Tight junction } \\
\text { protein ZO-1 }\end{array}$ & tjp1 & BX872029 & 0.87 & 0.48 & 0.55 & 0.85 & 0.45 & 0.54 & tjp1 & BC088825 & 2.36 & 2.84 & 1.21 \\
\hline * Claudin-11 & cldn11 & BX301535 & 0.77 & 0.37 & 0.48 & 0.43 & 0.16 & 0.39 & cldn11 & CB591807.1 & 1.90 & 2.66 & 1.40 \\
\hline${ }^{*}$ Tescalcin & tesc & BX877446 & 0.71 & 2.34 & 3.27 & 0.84 & 13.19 & 13.90 & tesc & NM_001095029 & 2.44 & 2.34 & 0.96 \\
\hline $\begin{array}{l}{ }^{*} 7- \\
\text { dehydrocholesterol } \\
\text { reductase }\end{array}$ & dher7 & BX884545 & 0.87 & 0.48 & 0.55 & 1.17 & 0.26 & 0.25 & dher7 & NM_001087087 & 1.96 & 1.79 & 0.91 \\
\hline
\end{tabular}

For each gene, official name, official symbol, GenBank accession number, and expression ratio among studied stages deduced from microarray and QPCR analyses are indicated. Target gene names are bolded when their expression profile during late oogenesis is similar in both species. Thirteen rainbow trout females were used for the transcriptomic analysis (FV, $n=3 ; P V, n=4$; females; Mat., $n=6$ ) [14], while 28 females (FV, $n=6$; PV, $n=14$ females; Mat., $n=8$ ) were used for QPCR, including the females used for the transcriptomic analysis.

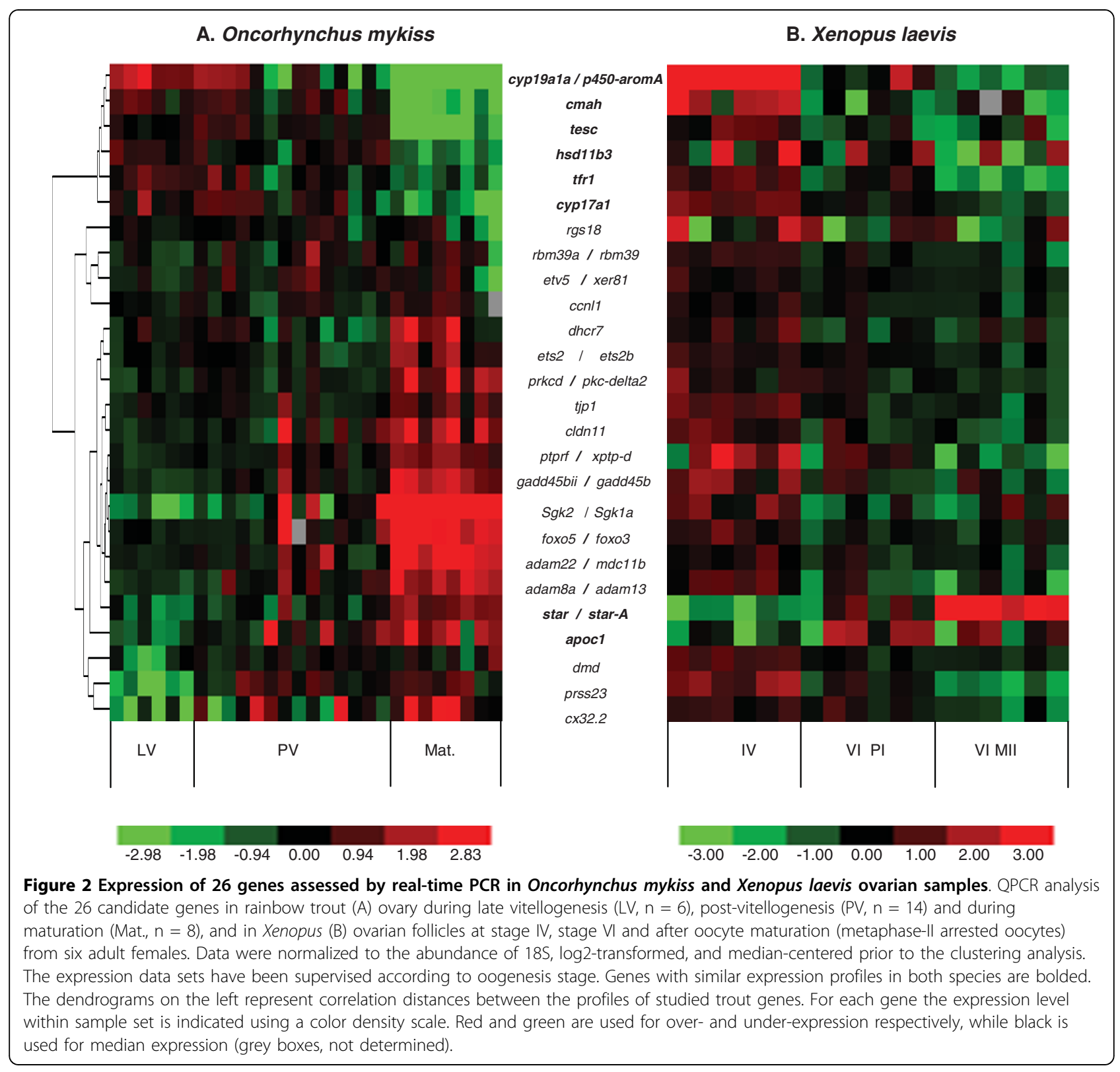




\section{Characterization of genes with known or suspected functions in steroidogenesis}

Among the eight genes exhibiting similar expression profiles in both species, four genes encode proteins with known or suspected functions in steroidogenesis and were further studied here. In addition, the apolipoprotein $\mathrm{C} 1$ (apoC1) may also be linked to steroidogenesis as the cholesterol necessary for ovarian steroidogenesis may come either from de novo synthesis or from lipoprotein cholesterol uptake. $A p o C 1$ was therefore selected for further analysis. In vertebrates, including rainbow trout and Xenopus, the orthology relationships of cytochrome P450 19A1 (cyp19a1) and STeroidogenic Acute Regulatory protein (star) are well characterized [17-20] (although star-A is the Xenopus official symbol, we will use star hereafter for both trout and Xenopus genes for clarity reason). In contrast, Xenopus orthologs of cyp 17a1, hsd11b3 and apoC1 had not been previously identified clearly. We thus performed specific phylogenetic analyses that are reported in additional files 3, 4 and 5 for cyp17a1, hsd11b3 and apoC1 respectively, to demonstrate orthology relationships between rainbow trout and Xenopus sequences.

The rainbow trout and Xenopus Cyp17a1 protein sequences exhibit $47 \%$ overall sequence identity with the cognate human protein. The rainbow trout Cyp17a1 protein sequence exhibits $61 \%$ sequence identity with cyp17a1 Xenopus sequence (Fig. 3). Three conserved domains have been characterized [21]. The domain I is composed of a heme-binding domain [22] and displays $71 \%$ of identity between human and trout sequences, and $79 \%$ of identity between trout and Xenopus sequences. The domain II is a conserved tridecapeptide, with a putative steroid-binding domain [23]. This domain is $77 \%$ identical between human and trout sequences and $87 \%$ between trout and Xenopus sequences. The domain III has been described as a CYP17 specific domain [21] and shows $62 \%$ of identity between human and trout sequences and $90 \%$ of identity between trout and Xenopus sequences. Finally, a mutation of the human ser-106 or a deletion of the three amino acids asp-487, ser-488 and phe-489 abrogate CYP17 activity [24,25]. Interestingly, these amino-acids are poorly conserved in non-mammalian vertebrates.

Fish Hsd11b3 is orthologous to Xenopus, chicken and human hsd11b3, also referred as hsd11b1-like (Additional file 4). Rainbow trout Hsd11b3 shares $49 \%$ and $47 \%$ identity with human and Xenopus proteins respectively (Fig. 4) while Xenopus and human sequences are $42 \%$ identical. Hsd $11 \mathrm{~b}$ proteins possess a superfamily Rossmann-fold NAD(P)H/NAD $(\mathrm{P})(+)$ binding domains composed of a glucose/ribitol dehydrogenase domain and a short chain dehydrogenase domain.
Finally, our phylogenetic analysis clearly demonstrated the orthology relationship of rainbow trout and Xenopus ApoC1 genes [see Additional file 5]. At the amino acid level, rainbow trout and Xenopus sequences share $36 \%$ of identity. The trout sequence is $23 \%$ identical to the human protein, while Xenopus sequence is $29 \%$ identical to the human protein (Fig. 5).

\section{Ovarian expression and tissue distribution of star in}

\section{rainbow trout and Xenopus}

Star mRNA expression shows a progressive increase during late and/or post-vitellogenesis and a sharp increase during maturation in both species (Fig. 6A and $6 \mathrm{~B})$. In rainbow trout, star mRNA abundance is two times higher during post-vitellogenesis than during late vitellogenesis and six times higher during maturation than during late vitellogenesis. In Xenopus laevis, star mRNA abundance is four times higher at prophase I of stage VI and 40 times higher at metaphase II of stage VI, when compared to stage IV follicles. Tissue analysis revealed a predominant expression in gonads of trout and Xenopus (Fig. 6C and 6D). The expression of star in Xenopus testis was 60 times higher than in ovary. In contrast, expression of star in trout testis was six times lower than in ovary. Low expression levels were also evidenced in trout intestine and to a less extent in other tissues. Star mRNA expression was also detected in Xenopus stomach.

\section{Ovarian expression and tissue distribution of aromatase} in rainbow trout and Xenopus

The cytochrome P450 aromatase (cyp19a1a for trout and $p 450$-arom- $A$ for Xenopus) expression shows a dramatic decrease during late oogenesis in both species (Fig. 7A and 7B). The transcript thus becomes barely detectable in matured follicles of both species. Tissue expression analysis confirms an ovarian-specific expression of the gonad gene (cyp19a1a) for trout (Fig. 7C) with no transcript evidenced in brain. When using primers that do not discriminate ovarian and cerebral aromatase mRNAs, we detected expression of aromatase mainly in Xenopus brain and ovary (Fig. 7D). The higher expression was detected in the brain and a weaker expression of aromatase mRNA was detected in testis, stomach and intestine.

Ovarian expression and tissue distribution of cyp17a1 in rainbow trout and Xenopus

cyp17a1 expression decreased from late and/or postvitellogenesis to the completion of oocyte maturation in both species, but in a slightly different manner (Fig. 8A and $8 \mathrm{~B}$ ). In trout, a significant four time reduction was evidenced only during maturation even if the decrease was initiated earlier, by the end of vitellogenesis. On the other hand, Xenopus cyp17a1 expression decreased significantly during late/post-vitellogenesis as shown by the 


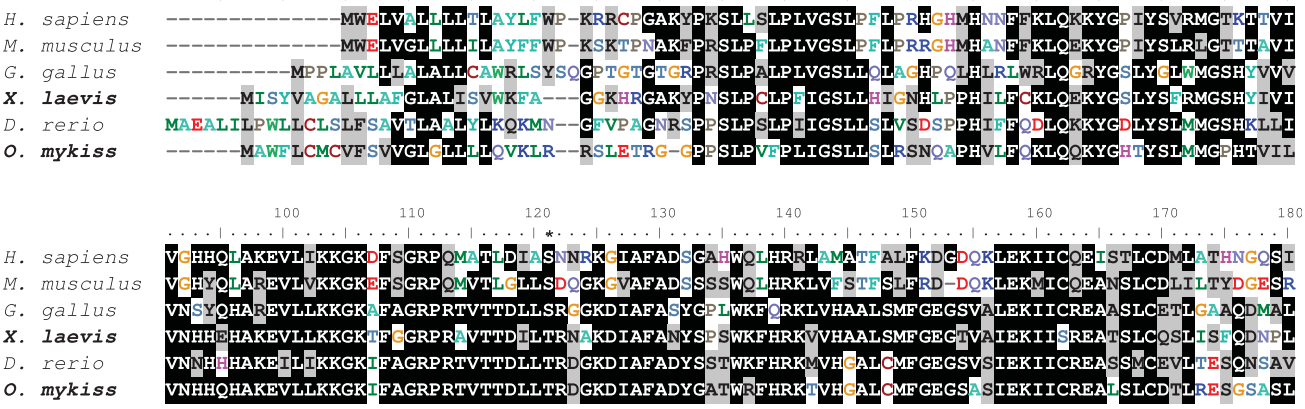

$$
\text { 0. mykiss }
$$
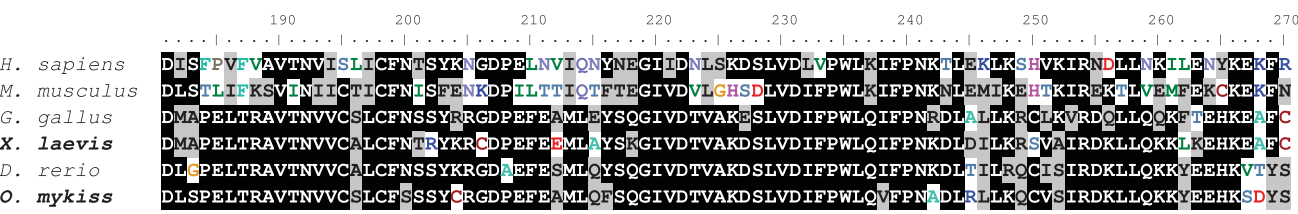

o. mykiss

$$
\begin{aligned}
& \text { H. sapiens } \\
& \text { M. musculus } \\
& \text { G. gallus } \\
& \text { X. laevis } \\
& \text { D. rerio } \\
& \text { O. mykiss }
\end{aligned}
$$

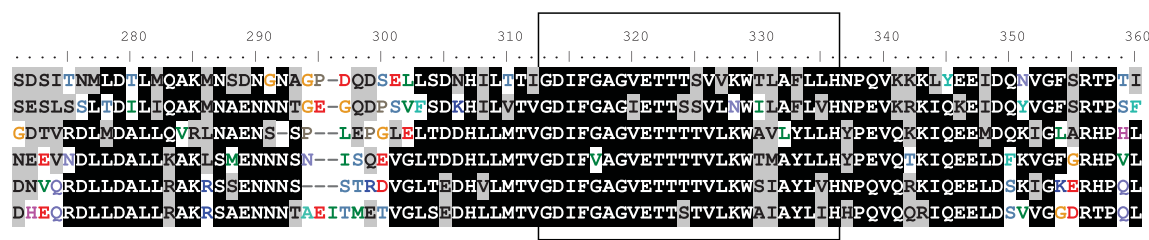

Domain I
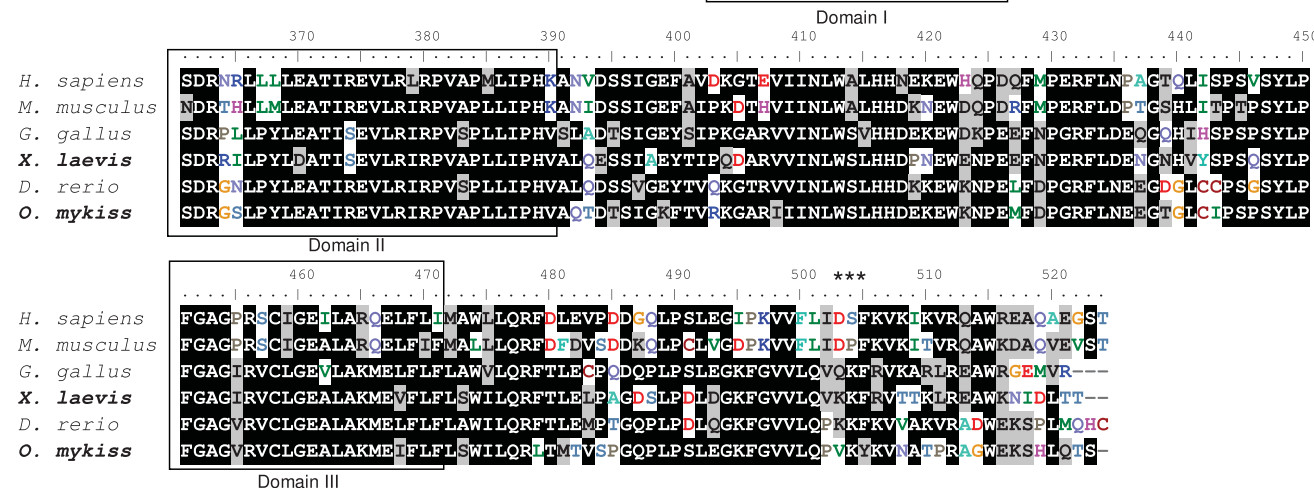

Figure 3 Cyp17a1 amino acid sequence alignments among vertebrates. Amino acid sequence alignments between human CYP17A1 (ENSG00000148795, H. sapiens), mouse Cyp17a1 (NP_031835.3, M. musculus), chicken CYP17A1 (ENSGALG00000008121 peptide

ENSGALP00000032532, G. gallus), clawed toad Cyp17a1 (AAG42003, X. laevis), zebrafish Cyp17a1 (AAl62669.1, D. rerio) and rainbow trout Cyp17a1 (NP_001118219.1, O. mykiss). Multiple amino acid sequence alignments were constructed using ClustalW software. The conserved domains previously identified are indicated: domain I (heme-binding domain [22]); domain II (putative steroid-binding domain [23]); domain III (CYP17 specific domain [21]). The amino acids that have been evidenced as essential for human CYP17 activity are indicated with asterisks (serine 106, aspartic acid 487, serine 488 and phenylalanine 489) $[24,25]$.

two time mRNA down-expression in oocytes from stage IV to stage VI. Then, the decrease of cyp17a1 was less important and not significantly different in follicles during oocyte progression from prophase I to metaphase II of meiosis. Tissue analyses showed that its expression was restricted to gonads in both species (Fig. 8C and $8 \mathrm{D})$.

Ovarian expression and tissue distribution of $h s d 11 b 3$ in rainbow trout and Xenopus

$h s d 11 b 3$ is nearly three-times less expressed during maturation than during late vitellogenesis in both trout and Xenopus (Fig. 9A and 9B). In trout, hsd11b3 expression significantly decreased at the time of oocyte maturation like in Xenopus. In the amphibian, the transcript reduction was already visible during late vitellogenesis but was not significant because of variable hsd11b3 mRNA levels measured in Xenopus stage IV follicles from different females. In contrast to the other three gene candidates analyzed above, $h s d 11 \mathrm{~b} 3$ was expressed in a more ubiquitous fashion (Fig. 9C and 9D). In trout and Xenopus, hsd11b3 was expressed in brain and intestine. Trout skin mRNA abundance was nine times higher than in the ovary, while no expression of $h s d 11 b 3$ was detected in Xenopus skin. Moreover no 


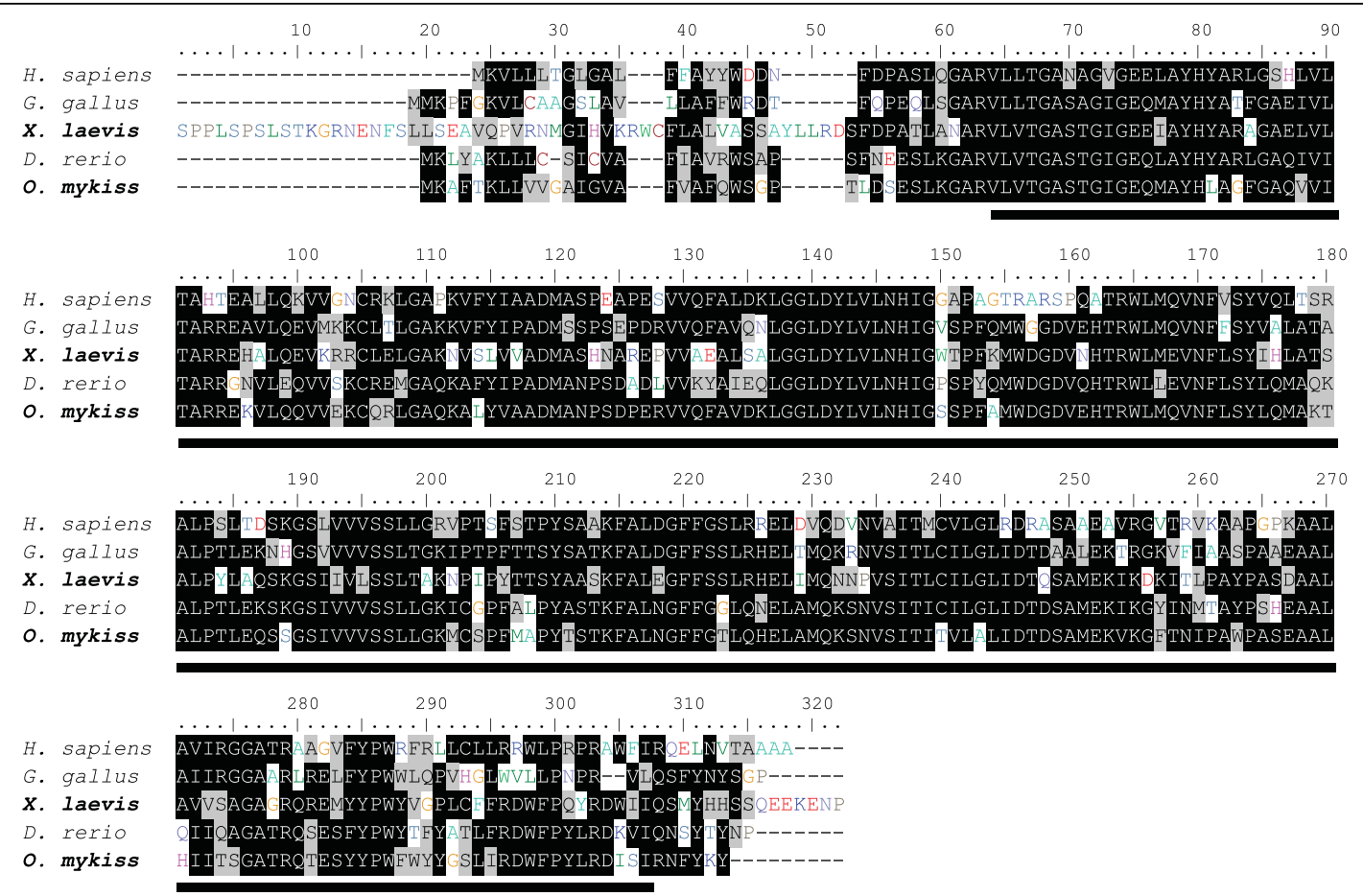

Figure 4 hsd11b3 amino acid sequence alignments among vertebrates. Amino acid sequence alignments between human HSD11B3 (ENSP00000340436, H. sapiens), chicken HSD11B3 (NP_001001201.1, G. gallus), clawed toad hsd11b3 (BC106472, X. laevis), zebrafish hsd11b3 (ENSDARG00000004562, D. rerio) and rainbow trout hsd11b3 (CA348069, O. mykiss). Multiple amino acid sequence alignments were constructed using ClustalW software. The superfamily Rossmann-fold NAD(P)H/NAD(P)(+) binding domain is underlined.

expression of hsd11b3 was detected in trout stomach, muscle, liver and heart while $h s d 11 b 3$ was expressed in these tissues in Xenopus.

Ovarian expression and tissue distribution of apoC1 in rainbow trout and Xenopus

ApoC1 mRNA level is four times more expressed during post-vitellogenesis than during late vitellogenesis in trout and Xenopus (Fig. 10A and 10B). Moreover, apoC1 expression increases dramatically during oocyte maturation in trout, while its expression slightly decreases during maturation in Xenopus but remains nearly three times higher than during late vitellogenesis. In trout and
Xenopus, apoC1 is mainly expressed by the liver and to a less extent, in the intestine, brain, stomach, ovary and testis (Fig. 10C and 10D).

\section{Discussion}

Identification of differentially expressed orthologous genes in both species

Among the twenty-six genes studied in the QPCR-based comparative analysis, eight genes had similar expression profiles throughout late oogenesis in both rainbow trout and Xenopus. These results indicate that our strategy which consisted in reanalyzing a transcriptomic study in

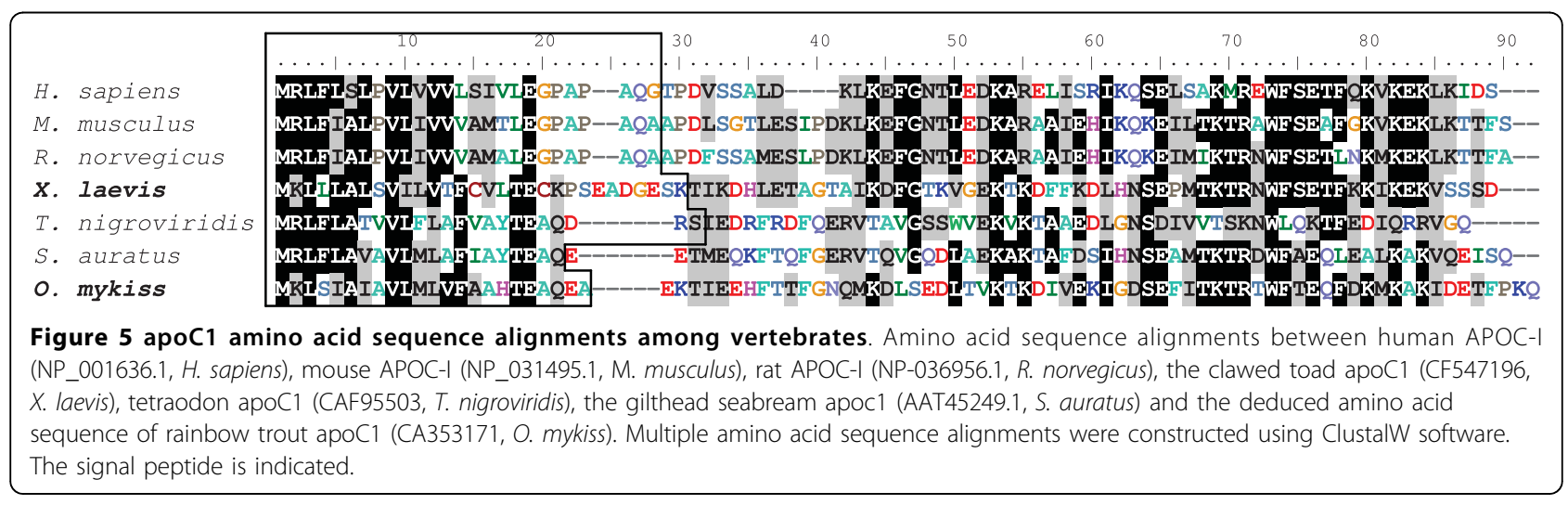




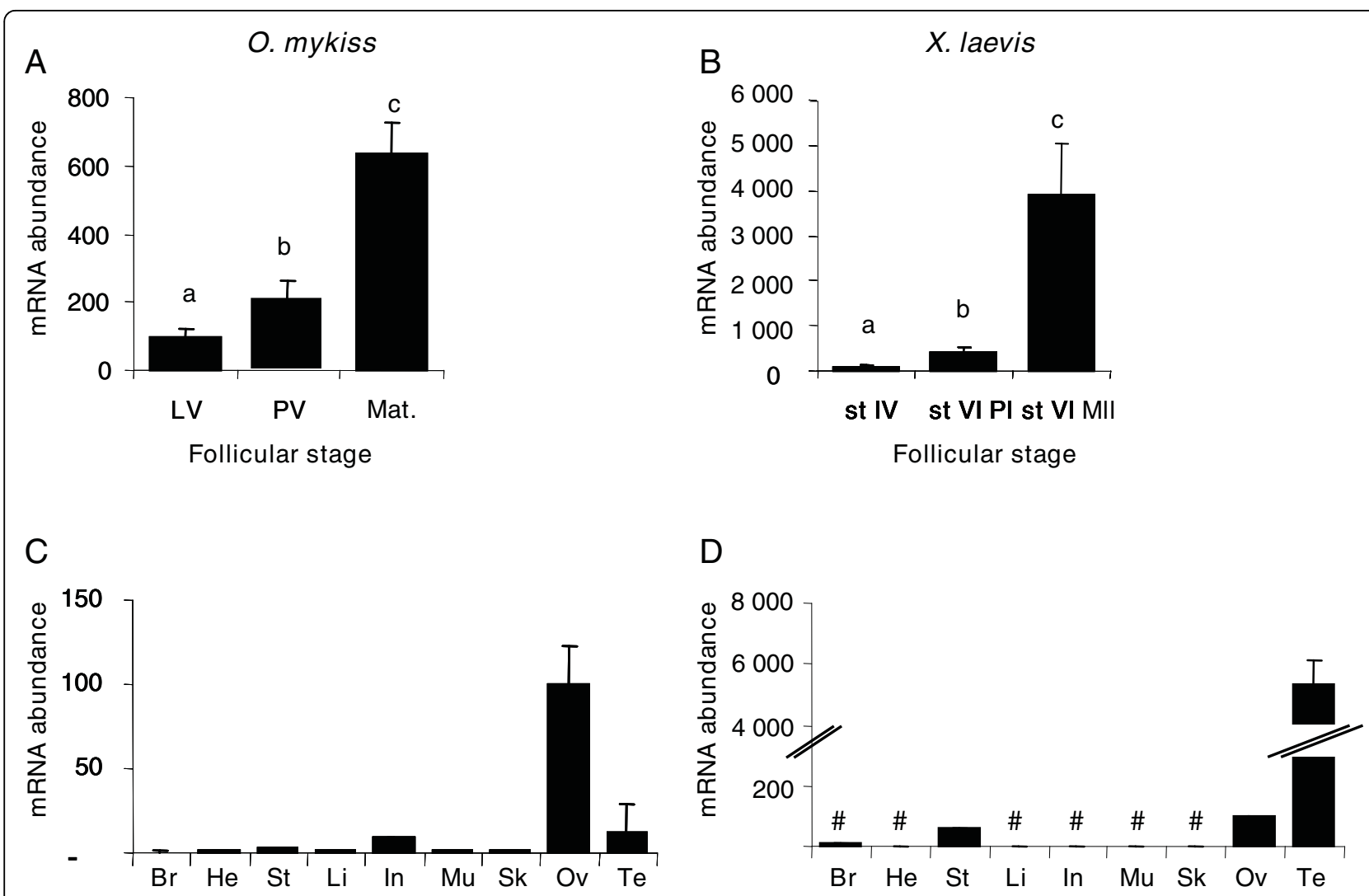

Figure 6 star expression profiles during late oogenesis and tissue expression profiles. Expression profiles of star in rainbow trout ovary sampled from females during late vitellogenesis $(L V, n=6)$, post-vitellogenesis $(P V, n=14)$ and during maturation $($ Mat., $n=8)(A)$, in Xenopus laevis ovarian follicles sampled from six females, at stage IV, stage VI and after in vitro maturation (st VI MII) (B). Expression of star mRNA in rainbow trout tissues: brain $(\mathrm{Br})$, heart $(\mathrm{He})$, stomach $(\mathrm{St})$, liver $(\mathrm{Li})$, intestine $(\mathrm{In})$, muscle $(\mathrm{Mu})$, skin $(\mathrm{Sk})$, post-vitellogenic ovary $(\mathrm{Ov})$, and testis $(\mathrm{Te})$ (C) and in Xenopus laevis tissues: brain (Br), heart (He), stomach (St), liver (Li), intestine (In), muscle (Mu), skin (Sk), ovary (Ov), testis (Te). Data were normalized to the abundance of $18 \mathrm{~S}$. Mean and SEM are shown. Bars sharing the same letter(s) are not significantly different $(p>0.05)$. In tissue, expression levels which are not significantly different from background signal are indicated with \#.

one species followed by a subsequent QPCR study in both species is relevant for the identification of orthologous genes that possibly participate in conserved molecular mechanisms among the two species. Among the eight genes exhibiting similar profiles in both species, five genes could be linked directly or indirectly to steroidogenesis, thus pointing out steroidogenic-related mechanisms as being possibly well conserved among fish and amphibians. Although gene expression of star, cyp19a1a and cyp17a1 have already been described in trout during late oogenesis $[14,26,27]$, none of these genes have been described at the mRNA level during this period in Xenopus. Moreover no expression data regarding $H s d 11 b 3$ and apoC1 are available in any of the studied species. Due to the predominant role of sex steroids in the control of the reproductive process in teleosts and amphibians $[2,10]$, these 5 genes were further studied in the present study.

While our approach has been successful, it should however be pointed out that a significant number of genes over-expressed during maturation in trout did not exhibit a similar pattern in Xenopus. These differences could be due to species-specific differences or even correspond to non-conserved mechanisms. Another possible explanation for the discrepancy between trout and Xenopus is that in the present study, trout oocyte maturation occurred naturally in vivo. In contrast, Xenopus oocyte maturation was triggered in vitro by a $15-\mathrm{h}$ incubation of isolated fully-grown follicles in medium supplemented with human chorionic gonadotropin (hCG). It is thus possible that the in vitro conditions did not trigger all the mechanisms that are naturally occurring in the preovulatory follicle, especially those involved in ovulation. Indeed, even if Xenopus injection of heterologous gonadotropin can lead to in vivo Xenopus oocyte maturation and ovulation [28], these processes can sometimes be uncoupled in vitro [29]. This could explain, in part, our results.

Finally, in order to identify Xenopus genes related to the trout candidates we used, as a high throughput 


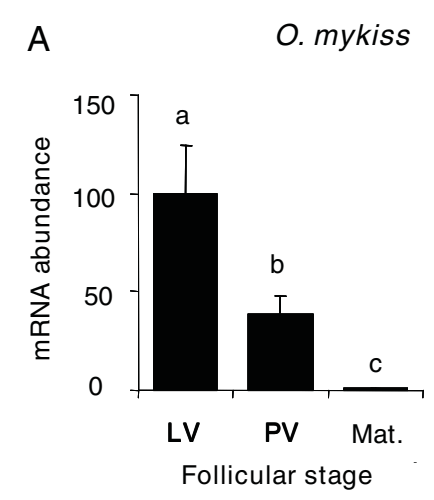

C

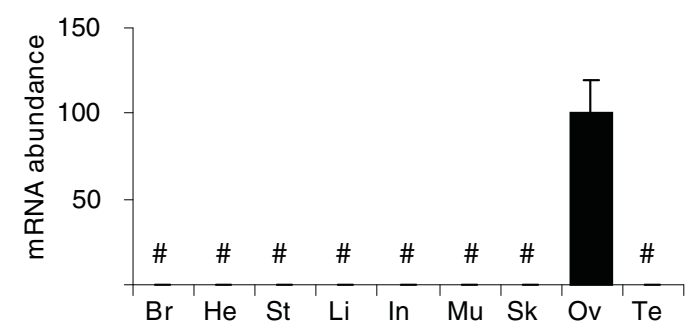

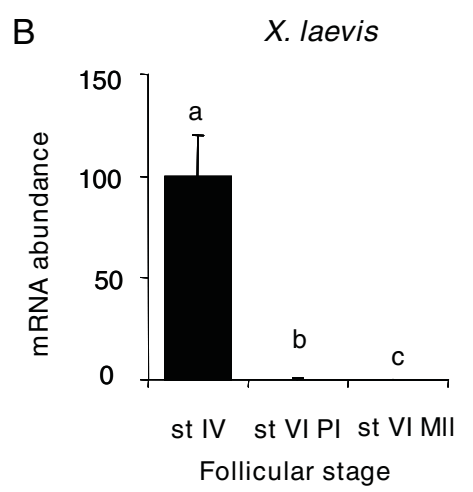

D

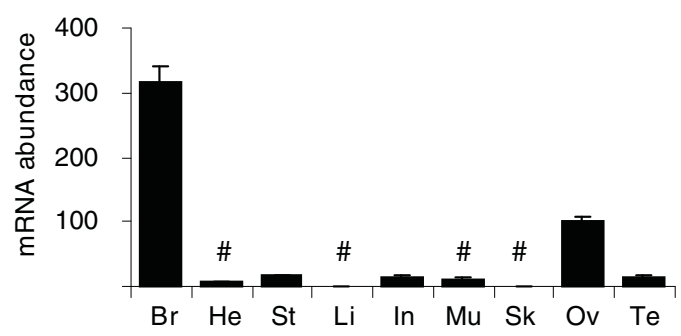

Figure 7 aromatase expression profiles during late oogenesis and tissue expression profiles. Expression profiles of aromatase (cyp19ala for trout and p450arom-A for Xenopus) during late oogenesis and in various tissues. Experiments were conducted in parallel for all genes. See fig. 6 legend for details.

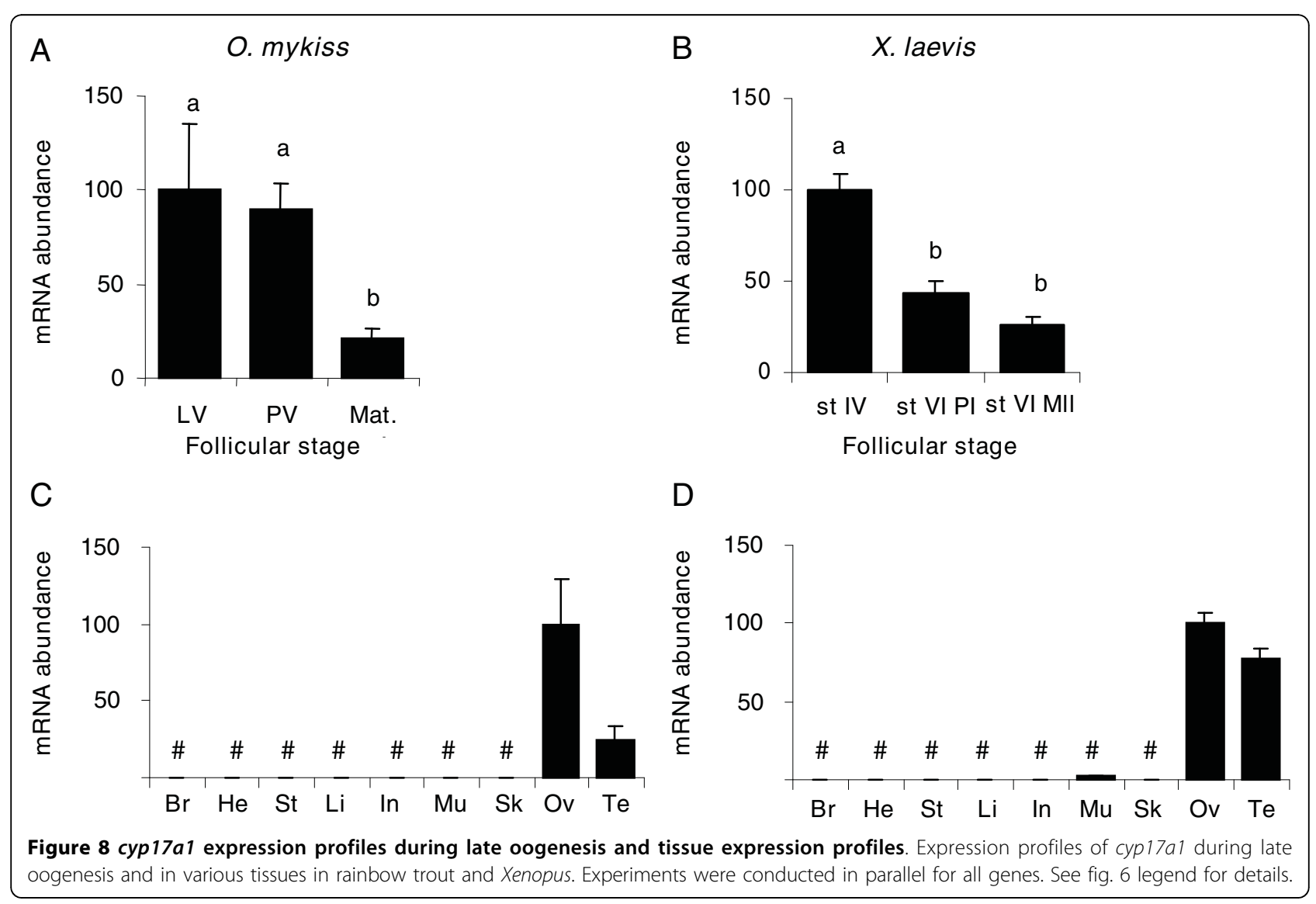




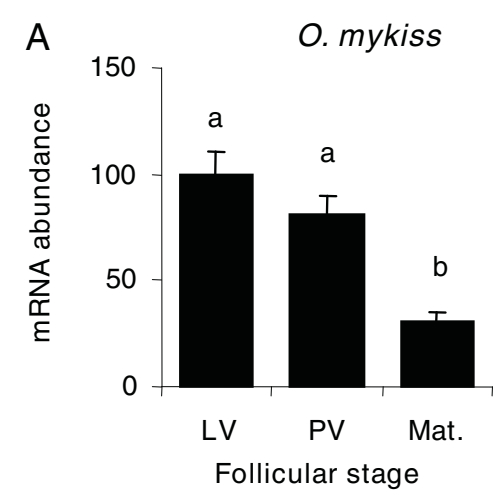

C

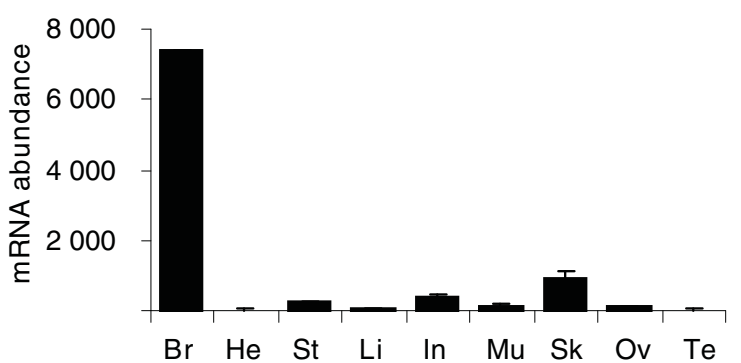

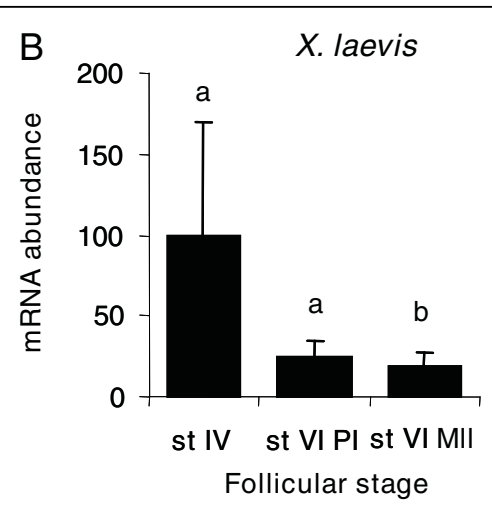

D

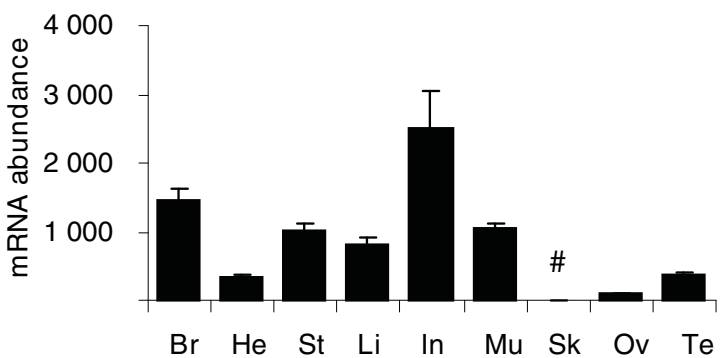

Figure 9 hsd 11 b3 expression profiles during late oogenesis and tissue expression profiles. Expression profiles of hsd $11 b 3$ for trout and Xenopus. Experiments were conducted in parallel for all genes. See fig. 6 legend for details.

approach, a best blast hit strategy. The orthology relationships between trout and Xenopus cognate proteins were then validated only for the five candidates that we subsequently analyzed. Thus, we cannot totally rule out that a part of the discrepancy between trout and Xenopus profiles could be due to a misidentification of true orthologs in Xenopus. This is especially true for adam $8 a$, adam 22 , foxo 5 and etv 5 genes that will require detailed phylogenic analyses.

\section{Candidate gene analysis}

\section{Star. STeroidogenic Acute Regulatory protein}

(Star) is involved in cholesterol shuttling across the mitochondrial membrane and its synthesis appears to be a limiting step in steroidogenesis [30-34]. In the present study, star was shown to be predominantly expressed in rainbow trout and Xenopus gonads. These results are in agreement with existing data in various vertebrates including teleosts $[19,20,33]$. Low expression levels were also detected in trout intestine and in Xenopus stomach. Although star expression has already been reported in rainbow trout intestine [19], no expression has been evidenced in digestive tract in any other species. While the over-expression during follicular maturation was previously documented in rainbow trout $[19,26]$, we showed for the first time that star is also over-expressed during hCG-induced oocyte maturation in Xenopus.
Interestingly, star expression is induced in response to gonadotropin stimulation in mammals and birds [30,35-38]. As oocyte maturation is induced in response to LH (Luteinizing Hormone) stimulation in fish and amphibians [2], it is likely that the strong star mRNA over-expression reported here in trout and Xenopus is also triggered by LH-mediated signaling pathway(s). In rainbow trout, it is also noteworthy that the circulating levels of the maturation-inducing steroid (MIS) detected during the preovulatory period [39] increase concomitantly with star mRNA levels. Likewise, in Xenopus laevis, progesterone and testosterone secretions are more important in stage VI follicles compared to stage IV follicles in agreement with star increased expression observed in this study [40]. Together, these results point out the over expression of star by gonadotropin during oocyte maturation as a possible conserved mechanism among non-mammalian vertebrates and possibly all vertebrates. The nature of the corresponding protein emphasizes the importance of steroidogenesis in the control of late oogenesis in non-mammalian vertebrates.

\section{Aromatase}

Aromatase is an enzyme (CYP19; EC 1.14.14.1) that converts androgens to estrogens. In most species including humans, chicken, Xenopus and a cartilaginous fish, a single gene has been isolated [41-44]. In contrast, in 

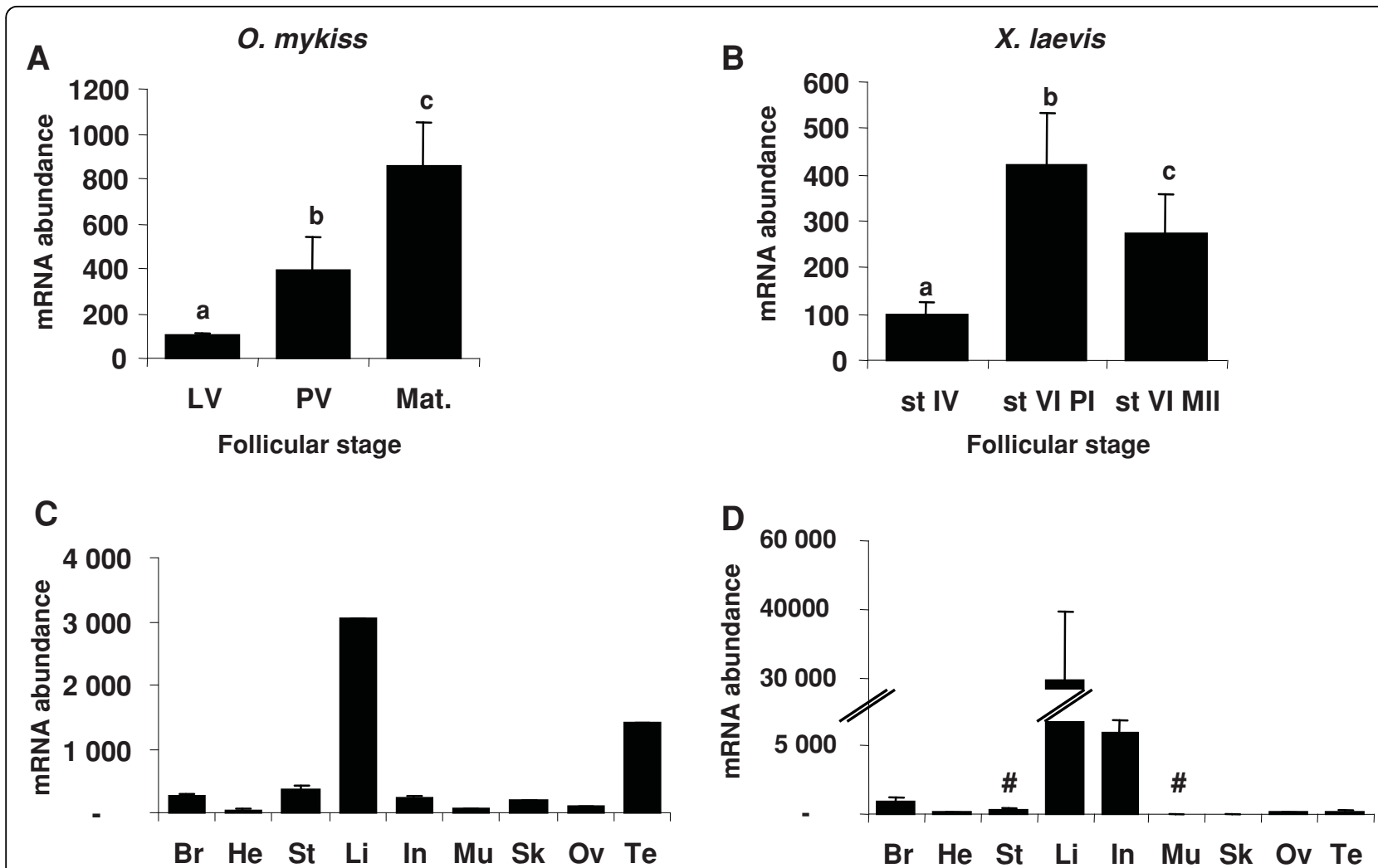

Figure 10 apoC1 expression profiles during late oogenesis and tissue expression profiles. Expression profiles of apoC 1 for trout and Xenopus. Experiments were conducted in parallel for all genes. See fig. 6 legend for details.

most teleosts, two genes, cyp19a1a (also referred as cyp 19a or cyp19a1) and cyp19a1b (also referred as cyp $19 b$ or cyp19a2), encode distinct proteins predominantly expressed in the ovary and the brain, respectively $[17,45-47]$. In the present study, we show that cyp19a1a is only expressed in trout ovary, while p450arom- $A$ is expressed mainly in Xenopus gonads and brain. The lack of cyp19a1a expression in rainbow trout brain is somewhat surprising as cyp19a1a has previously been detected in brain of various fish species [46-49]. The lack of expression of cyp19a1a in trout testis is, in contrast, in agreement with a previous study carried out in zebrafish [46]. In our study, a weak expression of aromatase was detected in Xenopus testis. This observation is consistent with a previous study reporting a weak expression but no aromatase activity in Xenopus laevis adult testis [50]. In Xenopus, we evidenced a very low expression in intestine and stomach, thus corroborating studies in human fetus which showed an aromatase expression in intestine [51,52].

The cytochrome P450 aromatase expression decreases dramatically during late oogenesis in both Xenopus and trout resulting in a barely detectable aromatase expression during maturation. Previous studies already indicated a decrease of aromatase expression [14,53-57] and activity [58] as well as a reduction of circulating E2 levels $[26,27,39,59]$ throughout late oogenesis in several fish species. However, we report here for the first time that aromatase transcript expression decreases dramatically in Xenopus post-vitellogenic, immature, follicles throughout late oogenesis. This observation is consistent with the decrease of aromatase and E2 production by the ovarian follicle during the post-vitellogenic period $[40,60]$. Together, these observations suggest that the drop of aromatase mRNA expression in the late oogenetic follicle is possibly a conserved molecular mechanism among non-mammalian vertebrates. In addition, existing data on the inhibition of oocyte maturation by E2 obtained in fish [61] as well as in another amphibian, Rana pipiens $[62,63]$ suggest that this mechanism of inhibition of precocious meiosis resumption could contribute to oocyte maturational competence acquisition in non-mammalian vertebrates.

\section{Cyp17a1}

The cytochrome P450 17A1, for which the official symbol is cyp17a1 is a member of the large superfamily of cytochrome P450. This enzyme (CYP17A1; EC = 1.14.99.9) acts as a $17 \alpha$-hydroxylase and a 17-20-lyase. The $17 \alpha$-hydroxylase activity converts progesterone and pregnenolone to $17 \alpha$-hydroxyprogesterone and 
$17 \alpha$-hydroxypregnenolone, respectively while the 17,20 lyase activity converts $17 \alpha$-hydroxypregnenolone to dehydroepiandrosterone (DHEA) and $17 \alpha$-hydroxyprogesterone to androstenedione. DHEA and androstenedione are precursors of testosterone and estrogen synthesis while $17 \alpha$-hydroxyprogesterone is a precursor of different progestins and cortisol. In teleosts, two genes have been identified [64]: Cyp17a1 (previously referred as $P 450-I$ ) and cyp17a2 (previously referred as P450-II). Cyp17a1 encodes a protein exhibiting both activities, as in other vertebrates, whereas cyp $17 a 2$ encodes a protein lacking 17,20 lyase activity.

Cyp17a1 is expressed in the gonads of both species, consistently with previous data in mammals [65], birds [66], and fish $[67,68]$, including rainbow trout $[26,27,69,70]$ but reported here for the first time in an amphibian species. In a previous study, a strong mRNA expression was also reported in rainbow trout kidney [70]. These authors also detected a low expression in various tissues using semi-quantitative RT-PCR that we were not able to confirm in the present work using QPCR. In both species, ovarian mRNA levels decrease dramatically throughout late oogenesis. In rainbow trout, the cyp17a1 profile was previously been documented $[26,27]$ and found to be consistent with previous Northern blot data indicating that cyp17a1 was abundant in the post-vitellogenic ovary as a result of an increase of expression that occurred during vitellogenesis [69]. Moreover, it has been shown in tilapia that cyp17a1 expression in granulosa cells decreases during late oogenesis, while cyp17a2 expression increases [64]. It should be however noticed that cyp17a1 expression during late oogenesis can be variable depending on the species $[67,71]$. Nevertheless, a low cyp17a1 mRNA expression was also reported in female fat head minnow close to full sexual maturity [68] and in two catfish populations, cyp17 mRNA level was shown to decrease throughout the period of spawning [55]. In rat, both cyp17a1 mRNA and protein abundance increase throughout folliculogenesis and subsequently decrease after hCG stimulation of preovulatory follicles [72]. Similarly, cyp17a1 mRNA expression decreased after LH surge in bovine preovulatory follicles [73]. Consistent with these observations was the report of a decrease of cyp17a1 mRNA expression in follicular layers of the preovulatory chicken follicles [56,74]. Together, existing and present observations suggest that even though species-specificity may exist, the decrease of cyp17a1 mRNA expression towards the end of oogenesis may be a well conserved molecular mechanism, possibly related to maturational competence acquisition. Indeed, Cyp17a1 could participate in the shift from E2 to maturation-inducing steroid production observed in fish and amphibians during late oogenesis $[40,75]$. In addition, Cyp17a1 could also participate in the production of androgens that have been evidenced to play important roles during late oogenesis in both amphibians and fish [76-78].

\section{Hsd11b3}

The 11beta-hydroxysteroid dehydrogenase isoenzymes HSD11B mainly catalyze the interconversion of active glucocorticoid (cortisol and corticosterone) and inactive 11-keto forms (cortisone and 11-dehydrocorticosterone) [79]. Three proteins have been described in mammals: HSD11B1, HSD11B2 and HSD11B3 (previously known as HSD11B1like or HSD11B1L). Previous analyses have indicated that hsd11b1 was not present in teleost species [80] and could only be found in amphibians, birds and mammals. In fish, Hsd11b2 has been characterized and shown to be expressed in various tissues such as gill, heart, intestine, ovary, testis and skin [79] and studied in more details in the ovary during late oogenesis $[79,81]$. Interestingly, hsd11b3 was phylogenetically characterized [80] but no expression data was available to date in fish and amphibians. In the present study, we show that $h s d 11 b 3$ mRNA is expressed in a large number of tissues but not in Xenopus skin while it is expressed mainly in brain, skin and intestine in trout. Thus, rainbow trout $h s d 11 b 3$ mRNA appears to have a more restricted tissue distribution than $h s d 11 b 2$ and tissue expression differs greatly between trout and Xenopus. Within the ovary, we evidence a decrease of $h s d 11 b 3$ transcript level throughout late oogenesis in both rainbow trout and Xenopus whereas $h s d 11 b 2$ mRNA has been reported to accumulate at the same time in trout female gonad [79,81].

At the functional level, HSD11B2 acts in mammals as a reductase and converts inactive cortisone to active cortisol. In fish, this isoform is also able to convert $11 \beta$ hydroxy-testosterone into 11 keto-testosterone (11-KT), which has been shown to be a major androgen steroid in fish [82]. In contrast, mammalian HSD11B1 predominantly acts in an opposite way, as likely does HSD11B3 according to the evolutionary history of the protein [80], since no functional study has been reported on this isoform. Likewise, fish Hsd11b3 is likely to act as the mammalian HSD11B1 and/or HSD11B3 (Additional file 4). Together, the expression profiles of $h s d 11 b 2[79,81]$ and $h s d 11 b 3$ (present results) in the rainbow trout preovulatory ovary suggest a combined role of these enzymes in gonad protection against any deleterious effect of stressinduced cortisol. Despite the lack of data on glucocorticoid levels and effects during oogenesis in amphibians, we may also hypothesize a similar role of Hsd11b3 during Xenopus late oogenesis. We cannot totally rule out a role of Hsd11b3 in regulating 11 ketotestosterone levels during follicular development and oocyte growth. Indeed, $11 \mathrm{KT}$, besides its well-known action in fish 
spermatogenesis, has been demonstrated as controlling oocyte growth, likely through lipid accumulation in eel [83] and in atlantic cod [84]. However, this cannot be extended to all teleosts as $11 \mathrm{KT}$ circulating levels are low or even undetectable in salmonid females [85-87]. Further investigations including protein expression and enzyme activity measurements are thus required to conclude on the exact physiological role(s) of these 11betahydroxysteroid dehydrogenase isoenzymes in ovarian functions during late oogenesis.

\section{ApoC1}

The apolipoprotein $\mathrm{C} 1$ belongs to the family of soluble apolipoproteins involved in cholesterol transport and uptake in vertebrates [88]. Interestingly, in vitro studies have also suggested that apoC1 could stimulate lecithincholesterol acyltransferase (LCAT) activity [89], thereby increasing the formation of esterified cholesterol as well as estradiol ester. In the present study, the tissue expression analysis reveals that apoC1 is primarily expressed in trout and Xenopus liver, but also in stomach, intestine and gonad. This result is consistent with previous studies performed in mammals [90-92] and in another teleost, Hemibarbus mylodon [93]. Only in the orange-spotted grouper, apoC1 could not be detected in the liver but it was nonetheless expressed in gonad and in brain [94].

Within the ovary, we show that apoC1 mRNA levels dramatically increase during late oogenesis in trout and Xenopus. This result confirms previous findings in trout [14] and in orange-spotted grouper [94]; only Tingaudsequeira $e t$ al. recently published in a marine flatfish ovary a different pattern of apoC1 expression, where its transcript levels significantly increase solely during follicle atresia following ovulation but not during follicle growth or maturation [95]. This study is also the first report on apoC1 expression in an amphibian. In mammals, ApoC1 expression in ovary during follicle development has not been studied to our knowledge but the increase of LCAT activity, correlated with a decrease of estradiol/progesterone ratio in antrum of human growing ovarian follicles [96] may indirectly reflect an increase of apoC1 expression. The function of ApoC1, accumulating during late oogenesis, remains to be elucidated. First, this apolipoprotein may have a role in remaining yolk degradation by the oocyte companion cells during follicle atresia [95] or yolk degradation as a nutrient source for early embryo development [94]. ApoC1 could also be involved in the regulation of steroidogenesis at least in two ways: (i) as an inhibitor of lipoprotein uptake via inhibition of lipoprotein binding to their receptors [97]; it may then modulate the ovarian cholesterol uptake during oogenesis; (ii) cholestryl and estradiol esters, formed upon LCAT activation by apoC1 [98], remain a source of bioactive metabolites in the steroid synthesis pathways. Interestingly, estradiol esters may also be involved in antioxydation processes [99]. Further studies will be required to fully understand the role(s) of $\mathrm{ApoC} 1$ during ovarian follicle development in vertebrates.

\section{Conclusions}

In the present study, we successfully used a QPCRbased comparative analysis to identify genes that are differentially expressed during both rainbow trout and Xenopus late oogenesis. Our observations point out several molecular mechanisms as possibly conserved among non-mammalian vertebrates. As an attempt to further characterize some of these mechanisms, we have characterized the sequence of some candidate proteins and thoroughly studied their mRNA expression in various tissues and during post-vitellogenesis in the two studied species. Our data show that the expression profiles of key steroidogenic enzymes are conserved during late oogenesis in Xenopus laevis ovarian follicles in agreement with existing data in rainbow trout. We indeed evidenced a decrease of the mRNA levels of cyp19a1 and cyp17a1 in both species and for the first time in an amphibian species. These expression patterns are consistent with the shift in steroidogenesis of ovarian follicles observed in both amphibians and teleost fish prior to meiosis resumption and could correspond to an important molecular mechanism of oocyte maturational competence acquisition common to these non-mammalian vertebrate groups. In contrast, the levels of star mRNA increase during oocyte maturation in both species. The nature of Star protein further stresses the importance of steroidogenesis in the post-vitellogenic process. The timing of star over-expression suggests, however, that Star would not be involved only in maturational competence acquisition but also in further follicular processes (e.g. ovulation) possibly through an increase of maturation-inducing steroid (MIS) synthesis. In addition, the decrease in hsd11b3 mRNA expression observed in both species throughout late oogenesis raises the question of the physiological role of this protein that will require further attention. Finally, the observed increase in apoC1 expression may be related to different mechanisms as steroidogenesis regulation through modulation of cholesterol uptake or through regulation of cholesteryl or estradiol esters synthesis. This increased expression may also be linked to yolk processing in the oocyte during late oogenesis or during early embryo development. The characterization of the function of this gene during late oogenesis requires however further investigation. Finally, other genes not related to steroidogenesis were also shown to have similar expression profiles in both species during late oogenesis. The identity of the proteins points out possibly conserved non-steroidogenic mechanisms that deserve future attention and specific investigations. 
Together, our results strongly suggest that comparative transcriptomics is an extremely valuable approach that must be pursued to gain insight in the conserved mechanisms underlying maturational and developmental competence acquisition in non-mammalian vertebrates.

\section{Methods}

\section{Animals and Tissue Collections}

Investigations and animal care were conducted in compliance with French and European regulation on the care and use of laboratory animals. Twenty eight adult rainbow trout females (Oncorhynchus mykiss) from an autumn-spawning strain were obtained at different stages of ovarian development from the INRA/PEIMA fish farm (Sizun, France). Ovaries were sampled during late vitellogenesis (LV, 3 or 4 weeks before expected spawning, $n=6$ ), in post-vitellogenesis ( $P V$, before oocyte maturation but during spawning period, $\mathrm{n}=14$ ) and during maturation (Mat., $\mathrm{n}=8$ ). Thirteen of these twenty eight females had previously been used for transcriptomic analysis [14]. For sampling, fish were deeply anaesthetised in $0,1 \%(\mathrm{v} / \mathrm{v}) 2$-phenoxyethanol in water and killed. Trout ovaries were then dissected out of the body cavity under sterile conditions.

Ovarian pieces were surgically removed from six Xenopus anaesthetised adult females (Xenopus laevis), purchased from NASCO (Fort Atkinson, WI, USA). 100 Xenopus stage IV (st IV, 800- $\mu \mathrm{m}$ diameter) and 50 stage VI (st VI PI, 1200- $\mu$ m diameter, in prophase I of meiosis) ovarian follicles [11] were manually isolated from ovarian pieces of each female. In order to obtain follicleenclosed oocytes in metaphase II of meiosis (st VI MII) from the same females, in vitro maturation was performed by incubating 50 immature stage VI follicles for $15 \mathrm{~h}$ at room temperature in OR2 buffer $(83 \mathrm{mM} \mathrm{NaCl}$, $2.5 \mathrm{mM} \mathrm{KCl}, 1 \mathrm{mM} \mathrm{CaCl} 2,1 \mathrm{mM} \mathrm{MgCl}_{2}, 1 \mathrm{mM}$ $\mathrm{Na}_{2} \mathrm{HPO}_{4}, 5 \mathrm{mM}$ HEPES, pH 7.4) supplemented with 40 $\mathrm{IU} / \mathrm{mL}$ of hCG (Organon, Puteaux, France). After the incubation period, germinal vesicle breakdown (GVBD) was assessed by direct observation under a stereomicroscope of the appearance of a white spot on the animal pole of the follicle-enclosed oocytes.

For tissue collection, three Xenopus adult females were sacrificed and different tissues (brain, heart, stomach, liver, intestine, muscle, skin, and ovary) were collected in addition to stage IV and VI follicles. The same tissues were also sampled from three different post-vitellogenic rainbow trout females. Trout testis samples were obtained from four different males at stage II (initiation of spermatogenesis) and stage $\mathrm{V}$ (spermiogenesis) whereas Xenopus testis samples were obtained from one male. Tissue samples were frozen in liquid nitrogen and stored at $-80^{\circ} \mathrm{C}$ until RNA extraction.

\section{Microarray data analysis}

Microarray data obtained from previous hybridization [14] were further reanalyzed. The rainbow trout generic array has been previously deposited in Gene Expression Omnibus (GEO) database (Platform\# GPL 3650; GEO accession GSE4871) [100]. In order to identify differentially expressed genes, a statistical analysis was carried out using Significance Analysis of Microarray (SAM) test [101]. Three 2-by-2 statistical analyses were performed in order to compare each group with the two other ones. For each comparison, 5\% of false discovery rate (FDR) was used to statistically discriminate differentially expressed genes. For clustering analysis, data were log2-transformed, median-centered, and an average linkage clustering was performed using CLUSTER software. Clusters were visualized using TREEVIEW software [102]. Gene Ontology (GO) analyses were performed using the NIH-DAVID web-based tool (Database for Annotation, Visualization, and Integrated Discovery) [103-105]. Enrichment analyses were realized using all the annotated genes present on the microarray (8 344 genes) as a reference and using UNIPROT accession IDs as input. Enriched GO biological process terms associated with each gene list were determined using modified Fisher's exact tests. GO terms with a raw pvalue lower than 0.05 are displayed [see additional files 1 and 2]. The number of genes associated with each GO term and associated enrichment information (raw pvalues and fold enrichment) are indicated for each GO term.

\section{Data mining and sequence analysis}

For all the clones identified as differentially abundant after the SAM analysis (Table 2), the official gene symbol was retrieved $[14,106,107]$ when possible and used in the text, figures and tables. The official Danio rerio gene symbol was used for the rainbow trout. Rainbow trout cDNA clones and corresponding IMAGE Xenopus clones were fully sequenced in both directions with the "PRISM* Ready Reaction Big Dye* Terminator cycle Sequencing Kit" and an automated ABI 310 sequencer (PE Biosystems, Courtaboeuf, France), as recommended by the manufacturer. Multiple amino acid sequence alignments were constructed using ClustalW software [108].

\section{Phylogenetic analysis}

In order to identify orthologous genes, phylogenetic analysis of studied genes was done using the FIGENIX phylogenomic analysis pipeline [109]. FIGENIX allows sequences retrieval, multiple sequence alignments, phylogenetic reconstruction and orthology and paralogy relationships deductions. The phylogenomic task was run using either trout or Xenopus amino acid sequence as a query, with the default parameters, and using 
Ensembl and NCBI-nr databases with search limited to mammals, chicken, Xenopus and fish.

\section{RNA extraction, reverse Transcription and Real-Time PCR} analysis

RNA extraction and reverse transcription were performed as previously described for rainbow trout [14]. For Xenopus, $5 \mu \mathrm{g}$ of total RNA were reverse transcribed using 200 units of SuperScript ${ }^{\mathrm{T} M}$ reverse transcriptase (Invitrogen, Cergy Pontoise, France) and 250 ng random hexamers (Promega) in a reverse transcription master mix containing $2 \mathrm{mM}$ dNTPs, $50 \mathrm{mM}$ Tris- $\mathrm{HCl}, 75 \mathrm{mM}$ $\mathrm{KCl}, 3 \mathrm{mM} \mathrm{MgCl}$, $10 \mathrm{mM}$ dithiothreitol, $\mathrm{pH}$ 8.3. Twenty-five units of RNase inhibitor (RNasin, Promega) were added to the reaction. RNA and dNTPs were denatured for $5 \mathrm{~min}$ at $65^{\circ} \mathrm{C}$, and then chilled on ice before addition of reverse transcription master mix. Reverse transcription was performed at $25^{\circ} \mathrm{C}$ for $10 \mathrm{~min}$ then at $42^{\circ} \mathrm{C}$ for $50 \mathrm{~min}$ followed by a 15 -min incubation step at $70^{\circ} \mathrm{C}$. For both species, control reactions were run without reverse transcriptase and used as negative controls in the real-time polymerase chain reaction (PCR) study for all target genes.

QPCR was done using a real-time PCR system Step One Plus (Applied Biosystems, Foster City, USA). Reverse transcription products were diluted to $1 / 25$ for trout and 1/20 for Xenopus. Triplicates were run for each RT product. Real-time PCR was performed using a real-time PCR kit provided with a SYBR Green fluorophore (Fast SYBR Green Master Mix, Applied Biosystem). Primer concentrations were $240 \mathrm{nM}$ for $18 \mathrm{~S}$ and $600 \mathrm{nM}$ for all other genes. The hot start enzyme was activated 20 seconds at $95^{\circ} \mathrm{C}$, then the amplification was carried out using the following cycle: $95^{\circ} \mathrm{C}$ for $3 \mathrm{sec} ; 60^{\circ}$ $\mathrm{C}$ for $30 \mathrm{sec}$; 40 times. A pool of reverse transcribed RNA was serially diluted and used to calculate a standard curve. For all studied genes, $18 \mathrm{~S}$ was used as an internal standard to normalize the signal. After amplification, a fusion curve was obtained according to the following protocol: $10 \mathrm{sec}$ holding followed by a $0.05^{\circ} \mathrm{C}$ increase, repeated 80 times, and starting at $55^{\circ} \mathrm{C}$. Primer sequences of studied genes are presented in supplementary data files (see additional file 6 for trout; see additional file 7 for Xenopus). The control reactions were used to calculate background expression level for each gene in order to evidence the tissues exhibiting expression levels significantly above background. Statistical analyses were performed using Statistica 7.0 software (Statsoft, Tulsa, OK). Regarding trout and Xenopus data, differences between groups were analyzed using non parametric U Mann-Whitney test and paired samples Wilcoxon test, respectively.
Additional file 1: Biological process enrichments of cluster 1 (= genes down-regulated during maturation). Gene Ontology functional annotations and biological process term enrichments were performed using the DAVID web-based tool (Database for Annotation, Visualization, and Integrated Discovery) [103104105]. Enrichment analyses were performed using all the annotated genes present on the microarray (8 344 genes) as the reference and using UNIPROT accession IDs as input for the differentially expressed genes. Enriched GO biological process terms associated with each gene list were determined using modified Fisher's exact tests. $\mathrm{GO}$ terms with a raw p-value lower than 0.05 are presented. The number of genes associated with each $\mathrm{GO}$ term and associated enrichment information (raw p-values, fold enrichment) are indicated for each GO term. Data are sorted by decreasing enrichment fold values.

Click here for file

[http://www.biomedcentral.com/content/supplementary/1471-2164-1118-S1.XLS]

Additional file 2: Biological process enrichments of cluster 2 (= genes up-regulated during maturation). Gene Ontology functional annotations and biological process term enrichments were performed using the DAVID web-based tool (Database for Annotation, Visualization, and Integrated Discovery) [103104105]. Enrichment analyses were performed using all the annotated genes present on the microarray (8 344 genes) as the reference and using UNIPROT accession IDs as input for the differentially expressed genes. Enriched GO biological process terms associated with each gene list were determined using modified Fisher's exact tests. $\mathrm{GO}$ terms with a raw p-value lower than 0.05 are presented. The number of genes associated with each GO term and associated enrichment information (raw $\mathrm{p}$-values, fold enrichment) are indicated for each GO term. Data are sorted by decreasing enrichment fold values.

Click here for file

[http://www.biomedcentral.com/content/supplementary/1471-2164-1118-S2.XLS]

Additional file 3: Phylogeny of cyp17a1 in vertebrates including fish. This npl tree is the fusion of neighbour joining (n), maximum parsimony (p), and maximum likelihood (I) trees calculated with the FIGENIX automated phylogenomic annotation pipeline [109]. The task was run using the Xenopus amino-acid sequence as a query. Protein sequence accession numbers for each species are given under brackets on the right of the figure. Evolutionary distances among sequences are represented by the tree structure, where branch length represents evolutionary distance. For each node, bootstrap values are reported for each $\mathrm{npl}$ method. Bootstrapping was carried out using 100 replications. Click here for file

[http://www.biomedcentral.com/content/supplementary/1471-2164-1118-S3.PDF ]

Additional file 4: Phylogeny of $h s d 11 b 3$ in vertebrates including fish. This $n p l$ tree is the fusion of neighbour joining (n), maximum parsimony (p), and maximum likelihood (I) trees calculated with the FIGENIX automated phylogenomic annotation pipeline [109]. Protein sequence accession numbers for each species are given under brackets on the right of the figure. Evolutionary distances among sequences are represented by the tree structure, where branch length represents evolutionary distance. For each node, bootstrap values are reported for each $\mathrm{npl}$ method. Bootstrapping was carried out using 100 replications. The task was run using the rainbow trout amino-acid sequence as a query.

Click here for file

[http://www.biomedcentral.com/content/supplementary/1471-2164-1118-S4.PDF ]

Additional file 5: Phylogeny of apoC1 in vertebrates including fish. This $\mathrm{npl}$ tree is the fusion of neighbour joining (n), maximum parsimony (p), and maximum likelihood (I) trees calculated with the FIGENIX automated phylogenomic annotation pipeline [109]. Protein sequence accession numbers for each species are given under brackets on the 
right of the figure. Evolutionary distances among sequences are represented by the tree structure, where branch length represents evolutionary distance. For each node, bootstrap values are reported for each $\mathrm{npl}$ method. Bootstrapping was carried out using 100 replications. The task was run using the Xenopus amino-acid sequence as a query. Click here for file

[http://www.biomedcentral.com/content/supplementary/1471-2164-1118-S5.PDF ]

Additional file 6: Primers used for the QPCR study in Oncorhynchus mykiss. For each target gene, full name, symbol, GenBank accession number and primers sequences are indicated.

Click here for file

[http://www.biomedcentral.com/content/supplementary/1471-2164-1118-S6.PDF ]

Additional file 7: Primers used for the QPCR study in Xenopus laevis For each target gene, full name, symbol GenBank accession number and primers sequences are indicated.

Click here for file

[http://www.biomedcentral.com/content/supplementary/1471-2164-1118-S7.PDF ]

\section{Acknowledgements}

This work was funded by ANR-08-GENM-033 (OSCILE). The authors thank Jerome Montfort from INRA UR1037 genomic facility and Marc Aubry from the Transcriptomic Biogenouest ${ }^{\circledR}$ platform for their support and advices in data analysis. The authors also thank Alexis Fostier (INRA UR1037) for helpful discussion and Thaovi Nguyen (INRA UR1037) for technical assistance. The authors are grateful to Stephane Dreano (CNRS UMR6061) for sequencing support. The authors also thank all INRA and CNRS experimental facility personnel (Sizun and Rennes) for animal care.

\section{Author details}

${ }^{1}$ CNRS/IGDR (UMR 6061), IFR140 GFAS, Université de Rennes I, 2, Avenue du Pr. Léon Bernard, 35043 Rennes Cedex, France. ${ }^{2}$ Institut National de la Recherche Agronomique, INRA SCRIBE, UR1037, IFR140 GFAS, Campus de Beaulieu, 35000 Rennes Cedex, France.

\section{Authors' contributions}

MG performed the microarray data analyses, real-time PCR experimentations, and drafted the manuscript. MG and FC extracted Xenopus RNA while JB extracted trout RNA. FC and JB designed and supervised the study, participated in the analyses and candidates selection and in the writing of the manuscript. All authors read and approved the final manuscript.

Received: 8 July 2009

Accepted: 8 January 2010 Published: 8 January 2010

\section{References}

1. Bobe J, Nguyen T, Fostier A: Ovarian function of the trout preovulatory ovary: new insights from recent gene expression studies. Comp Biochem Physiol A Mol Integr Physiol 2009, 153:63-68.

2. Jalabert B, Fostier A, Breton B, Weil C: Oocyte Maturation in Vertebrates. Vertebrate Endocrinology, Fundamentals and Biomedical Implications New York: Academic PressPang P, Schreibman M 1991, 4:23-90.

3. Yamashita M: Molecular mechanisms of meiotic maturation and arrest in fish and amphibian oocytes. Seminars in Cell \& Developmental Biology 1998, 9:569-579.

4. Jamnongjit M, Hammes SR: Oocyte maturation: the coming of age of a germ cell. Semin Reprod Med 2005, 23:234-241.

5. Pelegri F: Maternal factors in zebrafish development. Dev Dyn 2003, 228:535-554

6. Mtango NR, Potireddy S, Latham KE: Oocyte quality and maternal control of development. Int Rev Cell Mol Biol 2008, 268:223-290.

7. Matzuk MM, Burns KH, Viveiros MM, Eppig JJ: Intercellular communication in the mammalian ovary: oocytes carry the conversation. Science 2002, 296:2178-2180.
8. Jalabert B: Particularities of reproduction and oogenesis in teleost fish compared to mammals. Reprod Nutr Dev 2005, 45:261-279.

9. Jalabert B, Breton B, Bry C: Maturation and ovulation in vitro of rainbow trout Salmo gairdnerii ovocytes. Comptes Rendus de l'Académie des Sciences Paris 1972, 275:1139-42.

10. Rasar MA, Hammes SR: The physiology of the Xenopus laevis ovary. Methods Mol Biol 2006, 322:17-30.

11. Dumont JN: Oogenesis in Xenopus laevis (Daudin). I. Stages of oocyte development in laboratory maintained animals. J Morphol 1972, 136:153179 .

12. Lubzens E, Young G, Bobe J, Cerda J: Oogenesis in teleosts: how fish eggs are formed. Gen Comp Endocrinol 2009

13. Jalabert $B$ : In vitro oocyte maturation and ovulation in rainbow trout (Salmo gairdneri), northern pike (Esox lucius), and goldfish (Carassius auratus). Journal of Fisheries Research Board of Canada 1976, 33:974-988.

14. Bobe J, Montfort J, Nguyen T, Fostier A: Identification of new participants in the rainbow trout (Oncorhynchus mykiss) oocyte maturation and ovulation processes using cDNA microarrays. Reprod Biol Endocrinol 2006, 4:39.

15. Yoshizaki G, Patino R, Thomas P: Connexin messenger ribonucleic acids in the ovary of Atlantic croaker: molecular cloning and characterization, hormonal control, and correlation with appearance of oocyte maturational competence. Biol Reprod 1994, 51:493-503.

16. Eo J, Han K, Murphy M, Song H, Lim HJ: Etv5, an ETS transcription factor, is expressed in granulosa and cumulus cells and serves as a transcriptional regulator of the cyclooxygenase-2. J Endocrinol 2008, 198:281-290.

17. Tanaka M, Telecky TM, Fukada S, Adachi S, Chen S, Nagahama Y: Cloning and sequence analysis of the CDNA encoding $\mathrm{P}-450$ aromatase (P450arom) from a rainbow trout (Oncorhynchus mykiss) ovary; relationship between the amount of P450arom mRNA and the production of oestradiol-17 beta in the ovary. J Mol Endocrinol 1992, 8:5361.

18. Castro LF, Santos MM, Reis-Henriques MA: The genomic environment around the Aromatase gene: evolutionary insights. BMC Evol Biol 2005, 5:43.

19. Kusakabe M, Todo T, McQuillan HJ, Goetz FW, Young G: Characterization and expression of steroidogenic acute regulatory protein and MLN64 cDNAs in trout. Endocrinology 2002, 143:2062-2070.

20. Bauer MP, Bridgham JT, Langenau DM, Johnson AL, Goetz FW: Conservation of steroidogenic acute regulatory (StAR) protein structure and expression in vertebrates. Mol Cell Endocrinol 2000, 168:119-125.

21. Ono $H$, Iwasaki $M$, Sakamoto $N$, Mizuno S: cDNA cloning and sequence analysis of a chicken gene expressed during the gonadal development and homologous to mammalian cytochrome P-450c17. Gene 1988, 66:7785.

22. Gotoh O, Tagashira Y, lizuka T, Fujii-Kuriyama Y: Structural characteristics of cytochrome P-450. Possible location of the heme-binding cysteine in determined amino-acid sequences. J Biochem 1983, 93:807-817.

23. Ozols J, Heinemann FS, Johnson EF: Amino acid sequence of an analogous peptide from two forms of cytochrome P-450. J Biol Chem 1981, 256:11405-11408

24. Fardella CE, Zhang LH, Mahachoklertwattana P, Lin D, Miller WL: Deletion of amino acids Asp487-Ser488-Phe489 in human cytochrome P450c17 causes severe 17 alpha-hydroxylase deficiency. J Clin Endocrinol Metab 1993, 77:489-493.

25. Lin D, Black SM, Nagahama Y, Miller WL: Steroid 17 alpha-hydroxylase and 17,20-lyase activities of P450c17: contributions of serine106 and P450 reductase. Endocrinology 1993, 132:2498-2506.

26. Bobe J, Nguyen T, Jalabert B: Targeted Gene Expression Profiling in the Rainbow Trout (Oncorhynchus mykiss) Ovary During Maturational Competence Acquisition and Oocyte Maturation. Biol Reprod 2004, 71:7382.

27. Nakamura I, Evans JC, Kusakabe M, Nagahama Y, Young G: Changes in steroidogenic enzyme and steroidogenic acute regulatory protein messenger RNAs in ovarian follicles during ovarian development of rainbow trout (Oncorhynchus mykiss). Gen Comp Endocrinol 2005, 144:224-231.

28. Reynhout JK, Taddei C, Smith LD, LaMarca MJ: Response of large oocytes of Xenopus laevis to progesterone in vitro in relation to oocyte size and time after previous HCG-induced ovulation. Dev Biol 1975, 44:375-379. 
29. Schuetz AW: Hormonal dissociation of ovulation and maturation of oocytes: ovulation of immature amphibian oocytes by prostaglandin. Gamete Res 1986, 15:99-113.

30. Kerban A, Boerboom D, Sirois J: Human chorionic gonadotropin induces an inverse regulation of steroidogenic acute regulatory protein messenger ribonucleic acid in theca interna and granulosa cells of equine preovulatory follicles. Endocrinology 1999, 140:667-674.

31. Stocco DM, Clark BJ: Role of the steroidogenic acute regulatory protein (StAR) in steroidogenesis. Biochem Pharmacol 1996, 51:197-205.

32. King SR, Ronen-Fuhrmann T, Timberg R, Clark BJ, Orly J, Stocco DM: Steroid production after in vitro transcription, translation, and mitochondrial processing of protein products of complementary deoxyribonucleic acid for steroidogenic acute regulatory protein. Endocrinology 1995, 136:51655176.

33. Sugawara T, Holt JA, Driscoll D, Strauss JF, Lin D, Miller WL, Patterson D, Clancy KP, Hart IM, Clark BJ: Human steroidogenic acute regulatory protein: functional activity in COS-1 cells, tissue-specific expression, and mapping of the structural gene to $8 p 11.2$ and a pseudogene to chromosome 13. Proc Natl Acad Sci USA 1995, 92:4778-4782.

34. Clark BJ, Wells J, King SR, Stocco DM: The purification, cloning, and expression of a novel luteinizing hormone-induced mitochondrial protein in MA-10 mouse Leydig tumor cells. Characterization of the steroidogenic acute regulatory protein (StAR). J Biol Chem 1994, 269:28314-28322.

35. Kohen P, Castro O, Palomino A, Munoz A, Christenson LK, Sierralta W, Carvallo P, Strauss JF III, Devoto L: The steroidogenic response and corpus luteum expression of the steroidogenic acute regulatory protein after human chorionic gonadotropin administration at different times in the human luteal phase. J Clin Endocrinol Metab 2003, 88:3421-3430.

36. Sekar N, Lavoie HA, Veldhuis JD: Concerted regulation of steroidogenic acute regulatory gene expression by luteinizing hormone and insulin (or insulin-like growth factor I) in primary cultures of porcine granulosaluteal cells. Endocrinology 2000, 141:3983-3992.

37. Ronen-Fuhrmann T, Timberg R, King SR, Hales KH, Hales DB, Stocco DM, Orly J: Spatio-temporal expression patterns of steroidogenic acute regulatory protein (StAR) during follicular development in the rat ovary. Endocrinology 1998, 139:303-315.

38. Johnson AL, Bridgham JT: Regulation of steroidogenic acute regulatory protein and luteinizing hormone receptor messenger ribonucleic acid in hen granulosa cells. Endocrinology 2001, 142:3116-3124.

39. Fostier A, Jalabert B: Steroidogenesis in rainbow trout (Salmo gairdneri) at various preovulatory stages: changes in plasma hormone levels and in vivo and in vitro responses of the ovary to salmon gonadotropin. Fish Physiology and Biochemistry 1986, 2:87-99.

40. Fortune JE: Steroid production by Xenopus ovarian follicles at different developmental stages. Dev Biol 1983, 99:502-509.

41. Simpson ER, Michael MD, Agarwal VR, Hinshelwood MM, Bulun SE, Zhao Y: Cytochromes P450 11: expression of the CYP19 (aromatase) gene: an unusual case of alternative promoter usage. FASEB J 1997, 11:29-36.

42. McPhaul MJ, Noble JF, Simpson ER, Mendelson CR, Wilson JD: The expression of a functional CDNA encoding the chicken cytochrome P450arom (aromatase) that catalyzes the formation of estrogen from androgen. J Biol Chem 1988, 263:16358-16363.

43. Miyashita K, Shimizu N, Osanai S, Miyata S: Sequence analysis and expression of the P450 aromatase and estrogen receptor genes in the Xenopus ovary. J Steroid Biochem Mol Biol 2000, 75:101-107.

44. ljiri S, Berard C, Trant JM: Characterization of gonadal and extra-gonadal forms of the CDNA encoding the Atlantic stingray (Dasyatis sabina) cytochrome P450 aromatase (CYP19). Mol Cell Endocrinol 2000, 164:169-181.

45. Chiang EF, Yan YL, Tong SK, Hsiao PH, Guiguen Y, Postlethwait J, Chung BC: Characterization of duplicated zebrafish cyp19 genes. J Exp Zool 2001, 290:709-714

46. Kishida M, Callard GV: Distinct cytochrome P450 aromatase isoforms in zebrafish (Danio rerio) brain and ovary are differentially programmed and estrogen regulated during early development. Endocrinology 2001, 142:740-750

47. Tchoudakova A, Callard GV: Identification of multiple CYP19 genes encoding different cytochrome P450 aromatase isozymes in brain and ovary. Endocrinology 1998, 139:2179-2189.

48. Toffolo V, Belvedere $P$, Colombo L, Valle LD: Tissue-specific transcriptional initiation of the CYP19 genes in rainbow trout, with analysis of splicing patterns and promoter sequences. Gen Comp Endocrinol 2007, 153:311319.

49. Kwon JY, McAndrew BJ, Penman DJ: Cloning of brain aromatase gene and expression of brain and ovarian aromatase genes during sexual differentiation in genetic male and female Nile tilapia Oreochromis niloticus. Mol Reprod Dev 2001, 59:359-370.

50. Park JW, Hecker M, Murphy MB, Jones PD, Solomon KR, Van Der KG, Carr JA, Smith EE, du PL, Kendall RJ, Giesy JP: Development and optimization of a Q-RT PCR method to quantify CYP19 mRNA expression in testis of male adult Xenopus laevis: comparisons with aromatase enzyme activity. Comp Biochem Physiol B Biochem Mol Biol 2006, 144:18-28.

51. Toda K, Simpson ER, Mendelson CR, Shizuta Y, Kilgore MW: Expression of the gene encoding aromatase cytochrome P450 (CYP19) in fetal tissues. Mol Endocrinol 1994, 8:210-217.

52. Price T, Aitken J, Simpson ER: Relative expression of aromatase cytochrome P450 in human fetal tissues as determined by competitive polymerase chain reaction amplification. J Clin Endocrinol Metab 1992, 74:879-883.

53. Ings JS, Kraak Van der GJ: Characterization of the mRNA expression of StAR and steroidogenic enzymes in zebrafish ovarian follicles. Mol Reprod Dev 2006, 73:943-954.

54. Gen K, Okuzawa K, Kumakura N, Yamaguchi S, Kagawa H: Correlation between messenger RNA expression of cytochrome P450 aromatase and its enzyme activity during oocyte development in the red seabream (Pagrus major). Biol Reprod 2001, 65:1186-1194.

55. Kumar RS, ljiri S, Trant JM: Changes in the expression of genes encoding steroidogenic enzymes in the channel catfish (Ictalurus punctatus) ovary throughout a reproductive cycle. Biol Reprod 2000, 63:1676-1682.

56. Chang XT, Kobayashi T, Kajiura H, Nakamura M, Nagahama Y: Isolation and characterization of the cDNA encoding the tilapia (Oreochromis niloticus) cytochrome P450 aromatase (P450arom): changes in P450arom mRNA, protein and enzyme activity in ovarian follicles during oogenesis. J Mol Endocrinol 1997, 18:57-66.

57. Fukada S, Tanaka M, Matsuyama M, Kobayashi D, Nagahama Y: Isolation, characterization, and expression of cDNAs encoding the medaka (Oryzias latipes) ovarian follicle cytochrome P-450 aromatase. Mol Reprod Dev 1996, 45:285-290.

58. Young G, Kagawa $H$, Nagahama $Y$ : Evidence for a decrease in aromatase activity in the ovarian granulosa cells of amago salmon (Oncorhynchus rhodurus) associated with final oocyte maturation. Biol Reprod 1983, 29:310-315.

59. Goetz FW: Hormonal control of oocyte final maturation and ovulation in fishes. Fish Physiology New York: Academic PressHoar WS, Randall DJ, Donaldson EM 1983, IXB:117-170.

60. Mulner O, Thibier C, Ozon R: Steroid biosynthesis by ovarian follicles of Xenopus laevis in vitro during oogenesis. Gen Comp Endocrinol 1978, 34:287-295.

61. Jalabert B, Fostier A: The follicular sensitivity in vitro to maturationinducing hormones in rainbow trout, Salmo gairdneri: role of oestradiol17ß. Aqua 1984, 43:1-11.

62. Schuetz AW: Estrogens and ovarian follicular functions in Rana pipiens. Gen Comp Endocrinol 1972, 18:32-36.

63. Spiegel J, Jones E, Snyder BW: Estradiol-17 beta interference with meiotic maturation in Rana pipiens ovarian follicles: evidence for inhibition of 3 beta-hydroxysteroid dehydrogenase. J Exp Zool 1978, 204:187-191.

64. Zhou LY, Wang DS, Kobayashi T, Yano A, Paul-Prasanth B, Suzuki A, Sakai F, Nagahama Y: A novel type of P450c17 lacking the lyase activity is responsible for C21-steroid biosynthesis in the fish ovary and head kidney. Endocrinology 2007, 148:4282-4291.

65. Chung BC, Picado-Leonard J, Haniu M, Bienkowski M, Hall PF, Shively JE, Miller WL: Cytochrome P450c17 (steroid 17 alpha-hydroxylase/17,20 lyase): cloning of human adrenal and testis cDNAs indicates the same gene is expressed in both tissues. Proc Natl Acad Sci USA 1987, 84:407411.

66. Freking $F$, Nazairians $T$, Schlinger BA: The expression of the sex steroidsynthesizing enzymes CYP11A1, 3beta-HSD, CYP17, and CYP19 in gonads and adrenals of adult and developing zebra finches. Gen Comp Endocrinol 2000, 119:140-151.

67. Wang Y, Ge W: Cloning of zebrafish ovarian P450c17 (CYP17, 17alphahydroxylase/17, 20-lyase) and characterization of its expression in gonadal and extra-gonadal tissues. Gen Comp Endocrinol 2004, 135:241-249. 
68. Halm S, Kwon JY, Rand-Weaver M, Sumpter JP, Pounds N, Hutchinson TH, Tyler CR: Cloning and gene expression of P450 17alphahydroxylase,17,20-lyase cDNA in the gonads and brain of the fathead minnow Pimephales promelas. Gen Comp Endocrinol 2003, 130:256-266.

69. Sakai N, Tanaka M, Adachi S, Miller WL, Nagahama Y: Rainbow trout cytochrome P-450c17 (17 alpha-hydroxylase/17,20-lyase). cDNA cloning enzymatic properties and temporal pattern of ovarian P-450c17 mRNA expression during oogenesis. FEBS Lett 1992, 301:60-64.

70. Young G, Kusakabe M, Nakamura I, Lokman PM, Goetz FW: Gonadal Steroidogenesis in Teleost Fish. Molecular Aspects of Fish and Marine Biology Singapore: World Scientific Publishing Co.Melamed P, Sherwood N 2005, 4:155-223.

71. Kazeto $Y$, ljiri S, Todo T, Adachi S, Yamauchi K: Molecular cloning and characterization of Japanese eel ovarian P450c17 (CYP17) cDNA. Gen Comp Endocrinol 2000, 118:123-133.

72. Hedin L, Rodgers RJ, Simpson ER, Richards JS: Changes in content of cytochrome P450(17)alpha, cytochrome P450scc, and 3-hydroxy-3methylglutaryl $\mathrm{CoA}$ reductase in developing rat ovarian follicles and corpora lutea: correlation with theca cell steroidogenesis. Biol Reprod 1987, 37:211-223.

73. Voss AK, Fortune JE: Levels of messenger ribonucleic acid for cytochrome P450 17 alpha-hydroxylase and P450 aromatase in preovulatory bovine follicles decrease after the luteinizing hormone surge. Endocrinology 1993, 132:2239-2245

74. $\mathrm{Li}$ Z, Johnson AL: Expression and regulation of cytochrome P450 17 alpha-hydroxylase messenger ribonucleic acid levels and androstenedione production in hen granulosa cells. Biol Reprod 1993, 49:1293-1302

75. Nagahama Y: Endocrine regulation of gametogenesis in fish. Int J Dev Biol 1994, 38:217-229.

76. Jalabert B: Modulation of 17-alpha-hydroxy-20 beta-dihydroprogesterone or gonadotropic extract activity on the in vitro intrafollicular maturation of rainbow trout (Salmo gairdnerii) oocytes by various steroids lacking maturing activity. C R Acad Sci Hebd Seances Acad Sci D 1975, 281:811-4.

77. Lutz LB, Cole LM, Gupta MK, Kwist KW, Auchus RJ, Hammes SR: Evidence that androgens are the primary steroids produced by Xenopus laevis ovaries and may signal through the classical androgen receptor to promote oocyte maturation. Proc Natl Acad Sci USA 2001, 98:13728-13733.

78. Yang WH, Lutz LB, Hammes SR: Xenopus laevis ovarian CYP17 is a highly potent enzyme expressed exclusively in oocytes. Evidence that oocytes play a critical role in Xenopus ovarian androgen production. I Biol Chem 2003, 278:9552-9559.

79. Kusakabe M, Nakamura I, Young G: 11 beta-hydroxysteroid dehydrogenase complementary deoxyribonucleic acid in rainbow trout: cloning, sites of expression, and seasonal changes in gonads. Endocrinology 2003, 144:2534-2545.

80. Baker ME: Evolutionary analysis of 11 beta-hydroxysteroid dehydrogenase-type 1, -type 2, -type 3 and 17beta-hydroxysteroid dehydrogenase-type 2 in fish. FEBS Lett 2004, 574:167-170.

81. Milla $S$, Jalabert $B$, Rime $H$, Prunet $P$, Bobe J: Hydration of rainbow trout oocyte during meiotic maturation and in vitro regulation by 17,20 beta\}dihydroxy-4-pregnen-3-one and cortisol. J Exp Biol 2006, 209:1147-1156.

82. Borg B: androgens in teleost fishes. Comp Biochem Physiol C Pharmacol Toxicol Endocrinol 1994, 109:219-245.

83. Lokman PM, Kan G, Young G: Effects of steroid and peptide hormones on in vitro growth of previtellogenic oocytes from eel, Anguilla australis. Fish Physiol Biochem 2003, 28:283-285.

84. Kortner TM, Rocha E, Arukwe A: Previtellogenic oocyte growth and transcriptional changes of steroidogenic enzyme genes in immature female Atlantic cod (Gadus morhua L.) after exposure to the androgens 11-ketotestosterone and testosterone. Comp Biochem Physiol A Mol Integr Physiol 2009, 152:304-313.

85. Simpson $\mathrm{TH}$, Wright RS: A radioimmunoassay for 11-oxotestosterone: its application in the measurement of levels in blood serum of rainbow trout (S. gairdneri). Steroids 1977, 29(3):383-398.

86. Slater $\mathrm{CH}$, Schreck CB, Swanson P: Plasma profiles of the sex steroids and gonadotropins in maturing female spring chinook salmon (Oncorhynchus tshawytscha). Comp Biochem Physiol 1994, 109:165-175.

87. Lokman PM, Harris B, Kusakabe M, Kime DE, Schulz RW, Adachi S, Young G: 11-Oxygenated androgens in female teleosts: prevalence, abundance, and life history implications. Gen Comp Endocrinol 2002, 129:1-12.
88. Li WH, Tanimura M, Luo CC, Datta S, Chan L: The apolipoprotein multigene family: biosynthesis, structure, structure-function relationships, and evolution. J Lipid Res 1988, 29:245-271.

89. Jong MC, Hofker MH, Havekes LM: Role of ApoCs in lipoprotein metabolism: functional differences between ApoC1, ApoC2, and ApoC3. Arterioscler Thromb Vasc Biol 1999, 19:472-484.

90. Luo CC, Li WH, Chan L: Structure and expression of dog apolipoprotein $A-I, E$, and C-I mRNAs: implications for the evolution and functional constraints of apolipoprotein structure. J Lipid Res 1989, 30:1735-1746.

91. Lauer SJ, Walker D, Elshourbagy NA, Reardon CA, Levy-Wilson B, Taylor JM: Two copies of the human apolipoprotein C-I gene are linked closely to the apolipoprotein E gene. J Biol Chem 1988, 263:7277-7286.

92. Lenich C, Brecher P, Makrides S, Chobanian A, Zannis VI: Apolipoprotein gene expression in the rabbit: abundance, size, and distribution of apolipoprotein mRNA species in different tissues. J Lipid Res 1988, 29:755764.

93. Kim KY, Cho YS, Bang IC, Nam YK: Isolation and characterization of the apolipoprotein multigene family in Hemibarbus mylodon (Teleostei: Cypriniformes). Comp Biochem Physiol B Biochem Mol Biol 2009, 152:38-46.

94. Wang Y, Zhou L, Li Z, Gui JF: molecular cloning and expression characterization of Apoc-I in the orange-spotted grouper. Fish Physiol Biochem 2008, 34:339-348.

95. Tingaud-Sequeira A, Chauvigne F, Lozano J, Agulleiro MJ, Asensio E, Cerda J: New insights into molecular pathways associated with flatfish ovarian development and atresia revealed by transcriptional analysis. BMC Genomics 2009, 10:434.

96. Cigliano L, Balestrieri M, Spagnuolo MS, Dale B, Abrescia P: Lecithincholesterol acyltransferase activity during maturation of human preovulatory follicles with different concentrations of ascorbate, alphatocopherol and nitrotyrosine. Reprod Fertil Dev 2002, 14:15-21.

97. Jong MC, Havekes LM: Insights into apolipoprotein C metabolism from transgenic and gene-targeted mice. Int J Tissue React 2000, 22:59-66.

98. de Haan W, Out R, Berbee JF, Hoogt van der CC, van Dijk KW, van Berkel TJ, Romijn JA, Jukema JW, Havekes LM, Rensen PC: Apolipoprotein Cl inhibits scavenger receptor $\mathrm{BI}$ and increases plasma $\mathrm{HDL}$ levels in vivo. Biochem Biophys Res Commun 2008, 377:1294-1298.

99. Hockerstedt A, Jauhiainen M, Tikkanen MJ: Lecithin/cholesterol acyltransferase induces estradiol esterification in high-density lipoprotein, increasing its antioxidant potential. J Clin Endocrinol Metab 2004, 89:5088-5093.

100. GEO. http://www.ncbi.n/m.nih.gov/projects/geo/.

101. Tusher VG, Tibshirani R, Chu G: Significance analysis of microarrays applied to the ionizing radiation response. Proc Natl Acad Sci USA 2001, 98:5116-5121.

102. Eisen MB, Spellman PT, Brown PO, Botstein D: Cluster analysis and display of genome-wide expression patterns. Proc Natl Acad Sci USA 1998, 95:14863-14868.

103. Dennis G Jr, Sherman BT, Hosack DA, Yang J, Gao W, Lane HC, Lempicki RA: DAVID: Database for Annotation, Visualization, and Integrated Discovery. Genome Biol 2003, 4:3.

104. Huang DW, Sherman BT, Lempicki RA: Systematic and integrative analysis of large gene lists using DAVID bioinformatics resources. Nat Protoc 2009, 4:44-57.

105. DAVID Database for Annotation, Visualization, and Integrated Discovery. http://david.abcc.ncifcrf.gov/.

106. Hoffmann R, Valencia A: A gene network for navigating the literature. Nat Genet 2004, 36:664.

107. iHOP. http://www.ihop-net.org/.

108. Thompson JD, Higgins DG, Gibson TJ: CLUSTAL W: improving the sensitivity of progressive multiple sequence alignment through sequence weighting, position-specific gap penalties and weight matrix choice. Nucleic Acids Res 1994, 22:4673-4680.

109. Gouret P, Vitiello V, Balandraud N, Gilles A, Pontarotti P, Danchin EG: FIGENIX: intelligent automation of genomic annotation: expertise integration in a new software platform. BMC Bioinformatics 2005, 6:198.

doi:10.1186/1471-2164-11-18

Cite this article as: Gohin et al: Comparative transcriptomic analysis of follicle-enclosed oocyte maturational and developmental competence acquisition in two non-mammalian vertebrates. BMC Genomics 2010 11:18. 